OPEN ACCESS

Edited by: Fabrizio Ceciliani,

University of Milan, Italy

Reviewed by:

Jodi L. McGill,

lowa State University, United States

Sabine Hammer,

University of Veterinary Medicine

Vienna, Austria

*Correspondence:

Hung-Jen Liu

hiliu5257@nchu.edu.tw

${ }^{t}$ These authors have contributed equally to this work

Specialty section:

This article was submitted to

Comparative Immunology,

a section of the journal

Frontiers in Immunology

Received: 23 May 2020 Accepted: 21 October 2020 Published: 24 November 2020

Citation:

Tseng $\mathrm{H}-\mathrm{H}$, Huang $\mathrm{W}-\mathrm{R}$, Cheng $\mathrm{C}-\mathrm{Y}$, Chiu H-C, Liao T-L, Nielsen BL and

Liu H-J (2020) Aspirin and 5-

Aminoimidazole-4-carboxamide

Riboside Attenuate Bovine Ephemeral

Fever Virus Replication by Inhibiting

BEFV-Induced Autophagy.

Front. Immunol. 11:556838.

doi: 10.3389/fimmu.2020.556838

\title{
Aspirin and 5-Aminoimidazole-4- carboxamide Riboside Attenuate Bovine Ephemeral Fever Virus Replication by Inhibiting BEFV- Induced Autophagy
}

Hsu-Hung Tseng ${ }^{1,2 \dagger}$, Wei-Ru Huang ${ }^{1,3 \dagger}$, Ching-Yuan Cheng ${ }^{1}$, Hung-Chuan Chiu ${ }^{1,3}$,
Tsai-Ling Liao ${ }^{4,5,6}$, Brent L. Nielsen ${ }^{7}$ and Hung-Jen Liu ${ }^{1,3,5,6,8^{*}}$

1 Institute of Molecular Biology, National Chung Hsing University, Taichung, Taiwan, 2 Division of General Surgery, Taichung Hospital, Ministry of Health and Welfare, Taichung, Taiwan, ${ }^{3}$ The iEGG and Animal Biotechnology Center, National Chung Hsing University, Taichung, Taiwan, ${ }^{4}$ Department of Medical Research, Taichung Veterans General Hospital, Taichung, Taiwan, ${ }^{5}$ Rong Hsing Research Center for Translational Medicine, National Chung Hsing University, Taichung, Taiwan, ${ }^{6}$ Ph.D Program in Translational Medicine, National Chung Hsing University, Taichung, Taiwan, ${ }^{7}$ Department of Microbiology and Molecular Biology, Brigham Young University, Provo, UT, United States, ${ }^{8}$ Department of Life Sciences, National Chung Hsing University, Taichung, Taiwan

Recent study in our laboratory has demonstrated that BEFV-induced autophagy via activation of the PI3K/Akt/NF-KB and Src/JNK pathways and suppression of the PI3KAKt-mTORC1 pathway is beneficial for virus replication. In the current study, we found that both aspirin and 5-aminoimidazole-4-carboxamide-1- $\beta$-riboside (AICAR) siginificantly attenuated virus replication by inhibiting BEFV-induced autophagy via suppressing the BEFV-activated PI3K/Akt/NF- $\mathrm{KB}$ and Src/JNK pathways as well as inducing reversion of the BEFV-suppressed PI3K-Akt-mTORC1 pathway. AICAR reversed the BEFV-activated PI3K/Akt/NF-KB and Src/JNK pathways at the early to late stages of infection and induced reversion of the BEFV-suppressed PI3K-AKt-mTORC1 pathway at the late stage of infection. Our findings reveal that inhibition of BEFV-induced autophagy by AICAR is independent of AMPK. Furthermore, we found that AICAR transcriptionally downregulates the ATG related genes ULK1, Beclin 1, and LC3 and enhances Atg7 degradation by the proteasome pathway. Aspirin suppresses virus replication by inhibiting BEFV-induced autophagy. It directly suppressed the NF- $\mathrm{kB}$ pathway and reversed the BEFV-activated Src/JNK pathway at the early stage of infection and reversed the BEFV-suppressed PI3K $\mathrm{Akt} / \mathrm{mTOR}$ pathway at the late stage of infection. The current study provides mechanistic insights into the effects of aspirin and AICAR on BEFV replication through suppression of BEFV-induced autophagy.

Keywords: 5-aminoimidazole-4-carboxamide-1- $\beta$-riboside, aspirin, PI3K/Akt/NF-kB, autophagy, bovine ephemeral fever virus 


\section{INTRODUCTION}

Bovine ephemeral fever (BEF) is an acute febrile illness of cattle and water buffalo. Clinically, it is characterized by sudden onset of fever, stiffness, depression, nasal discharges, joint pain, and lameness in three days (1). Although the mortality rate is low, there are serious economic impacts including loss of milk production in widespread regions of Africa, the Middle East, Asia, and Australia (2). To date, treatment of BEF is mainly supportive and symptomatic. BEFV is a negative, single stranded RNA virus belonging to the rhabdovirus family in the order of Mononegavirales. BEFV virions are cone shaped (3), composed of a single-stranded, negative-sense RNA genome with a lipid envelope and five structural proteins, (L, P, G, N, and M) (4). The matrix (M) protein of BEFV is a nucleocytoplasmic shuttling protein (5) and is essential for virus maturation, budding, and regulation of the expression of viral and host proteins (6). It also plays an important role in inducing autophagy during BEFV infection (7). The PI3K/Akt signaling pathway and its downstream target, the mammalian target of rapamycin (mTOR), are involved in the regulation of diverse cellular functions. Many viruses target and hijack this pathway for host cell entry or viral protein translation $(8,9)$, especially for RNA synthesis of non-segmented, negative-stranded RNA viruses (9). An earlier study has shown that inhibition of PI3K and mTOR has positive effects on BEFV replication (10). Cell entry of BEFV follows a clathrin-mediated and dynamin 2-dependent endocytosis pathway that requires Rab5 and Rab7 as well as microtubules (11). In addition, upregulation of the PI3K-AktNF- $\kappa \mathrm{B}$ and Src-JNK-AP1 pathways by BEFV are essential not only for cell entry (12) but also trigger autophagy for virus replication (7). During cell entry, BEFV also triggers cyclooxygenase-2 (Cox-2)-catalyzed prostaglandin E2 (PGE2) synthesis and induces expressions of G-protein-coupled Eprostanoid (EP) receptors 2 and 4, leading to amplification of these pathways (12). Aspirin, acetylsalicylic acid, is one of the commonly used non-steroidal anti-inflammatory drugs (NSAID) for analgesic, antipyretic, and anti-inflammatory therapy. It causes an irreversible inactivation of Cox-1 and Cox-2 and sequentially inhibits the formation of PGE2, thus reducing the inflammation reaction (13). This infers an inhibitory role of aspirin to BEFV.

Autophagy can be induced by interplays between AMPactivated protein kinase (AMPK), mTOR, and Unc-51 like autophagy activating kinase (ULK 1/2) (14). It was reported that mTOR serves as a main gate way to autophagy under amino acid stimulation (15). mTOR complex 1 (mTORC1) is a repressor of autophagy under nutrient sufficiency conditions (16). In energy critical situations, AMPK induces autophagy by activating ULK $1 / 2$ and by suppressing mTORC1 through activating tuberous sclerosis complex 2 (TSC2) or inhibiting the regulatory-associated protein of mTOR (raptor) $(17,18)$. Our recent study has shown that BEFV induces autophagy by suppression of mTORC1 (7). It is interesting to examine if AMPK is involved in BEFV-induced autophagy. AMPK can be activated indirectly by a modulator that causes AMP or calcium accumulation or directly binds to and activates AMPK by conformational changes (19). 5-aminoimidazole-4-carboxamide riboside (AICAR) is a common AMPK activator; it is metabolized to AICAR 5'-monophosphate (ZMP) to bind to the AMPK $\gamma$ subunit without changing the ADP : ATP ratio or altering oxygen uptake (20). Interestingly, our findings reveal that AICAR inhibits BEFV-induced autophagy in an AMPK-independent mechanism. Collectivelly, the study provides mechanistic insights into aspirin- and AICAR-modulated inhibition of BEFV-induced autophagy via suppressing the BEFV-activated $\mathrm{PI3K} / \mathrm{Akt} / \mathrm{NF}-\kappa \mathrm{B}$ and Src/JNK pathways as well as reversion of $\mathrm{BEFV}$-inactivated $\mathrm{PI} 3 \mathrm{~K} / \mathrm{Akt} / \mathrm{mTORC} 1$, thereby inhibiting virus replication.

\section{MATERIALS AND METHODS}

\section{Virus Titration}

Madin-Darby bovine kidney (MDBK) cells were infected with BEFV for $24 \mathrm{~h}$. The supernatant containing BEFV particles was collected and serially diluted with serum-free DMEM. Each serial diluted virus solution $(200 \mu \mathrm{l})$ was seeded in a 24 -well-plate to incubate with the MDBK cells for $1 \mathrm{~h}$. Unabsorbed viruses were removed by washing the cells with phosphate buffered saline (PBS). Then, the cells were overlaid with DMEM containing 2\% FBS and $0.6 \mathrm{ml}$ of $0.8 \%$ agarose. After incubation at $37^{\circ} \mathrm{C}$ for 2 to 3 days. BEFV formed plaques staining by neutral red for $3 \mathrm{~h}$ were counted.

\section{Cells and Viruses}

MDBK cells were cultured in Dulbecco's modified eagle medium (DMEM) supplemented with $10 \%$ fetal bovine serum (FBS). $\left(1 \times 10^{6}\right)$ cells were seeded in $6-\mathrm{cm}$ cell culture dishes one day before initiating the experiment and were incubated at $37^{\circ} \mathrm{C}$ with $5 \% \mathrm{CO}_{2}$. The 2004/TW/TN1 strain of BEFV was propagated in MDBK cells. The supernatants of BEFV-infected cells were harvested when $70 \%-80 \%$ cytopathic effect (CPE) was detected, and then concentrated by Polyethylene glycol (PEG) 6000 precipitation. The harvested $\mathrm{BEF}$ viruses were dialysed and resuspended in phosphate-buffered saline (PBS), then stored at $-70^{\circ} \mathrm{C}$ before use.

\section{Chemical Inhibitors and Reagents}

5 -aminoimidazole-4-carboxamide-1- $\beta$-riboside (AICAR) and Furancarboxylic acid were purchased from Calbiochem Co. (San Diego, USA). Aspirin, indomethacin, MG132, and NS-398 (Cox-2 specific inhibitor) were purchased from Sigma-Aldrich Co. Prostaglandin E2 (PGE2) EIA kit was purchased from Cayman Chemical Co. (Ann Arbor, USA).

\section{Antibodies}

The catalog numbers and dilution factor of the primary antibodies antibodies used in this study are shown in Table $\mathbf{1}$. Polyclonal antibodies against the BEFV $\mathrm{M}$ protein are from our laboratory stock. Anti-rabbit IgG $(\mathrm{H}+\mathrm{L})$ and anti-mouse IgG $(\mathrm{H}+\mathrm{L})$ antibodies were purchased from Kirkegaard \& Perry Laboratories (Washington, DC., USA). 
TABLE 1 | The catalog numbers and dilution factor of the respective antibodies used in this study.

\begin{tabular}{|c|c|c|c|c|}
\hline Antibodies & $\begin{array}{c}\text { Catalog } \\
\text { numbers }\end{array}$ & $\begin{array}{l}\text { Clone } \\
\text { name }\end{array}$ & Dilutionfactor & Manufacture \\
\hline Mouse anti-M & - & - & 2000 & Our laboratory \\
\hline $\begin{array}{l}\text { Rabbit anti-p-mTOR } \\
\text { (S2448) }\end{array}$ & 2971 & ND & 1500 & Cell Signaling \\
\hline Rabbit anti-mTOR & 2983 & $7 \mathrm{C} 10$ & 3000 & Cell Signaling \\
\hline $\begin{array}{l}\text { Rabbit anti-p-PI3K p85 } \\
\text { (Y458) }\end{array}$ & 4228 & ND & 2000 & Cell Signaling \\
\hline Rabbit anti-PI3K p85 & 4257 & $19 \mathrm{H} 8$ & 2000 & Cell Signaling \\
\hline $\begin{array}{l}\text { Rabbit anti-p-Akt } \\
\text { (T308) }\end{array}$ & 2965 & C31E5E & 3000 & Cell Signaling \\
\hline $\begin{array}{l}\text { Rabbit anti-p-Akt } \\
\text { (S473) }\end{array}$ & 3787 & 736E11 & 2000 & Cell Signaling \\
\hline Rabbit anti-Akt & 2964 & 5B5 & 3000 & Cell Signaling \\
\hline Rabbit anti-Atg7 & 8558 & D12B11 & 3000 & Cell Signaling \\
\hline Rabbit anti-Beclin 1 & 3495 & D40C5 & 1500 & Cell Signaling \\
\hline Mouse anti-ІкB $\alpha$ & 4814 & L35A5 & 3000 & Cell Signaling \\
\hline Rabbit anti-p65 & 4764 & C22B4 & 2000 & Cell Signaling \\
\hline Rabbit anti-p50 & 3035 & ND & 2000 & Cell Signaling \\
\hline $\begin{array}{l}\text { Rabbit anti-histone } \\
\mathrm{H} 2 \mathrm{~A}\end{array}$ & 2578 & ND & 2000 & Cell Signaling \\
\hline $\begin{array}{l}\text { Mouse anti-p-Bcl-2 } \\
\text { (S70) }\end{array}$ & O5-613 & ND & 1500 & Upstate \\
\hline Mouse anti-Bcl-2 & 15071 & 124 & 3000 & Cell Signaling \\
\hline Rabbit anti-p62 & 7695 & D10E10 & 2000 & Cell Signaling \\
\hline $\begin{array}{l}\text { Rabbit anti-p-Src } \\
(Y 416)\end{array}$ & 2113 & 100F9 & 1500 & Cell Signaling \\
\hline Mouse anti-Src & 2110 & L4A1 & 3000 & Cell Signaling \\
\hline $\begin{array}{l}\text { Rabbit anti-p-SAPK } \\
\text { JNK (T183/Y185) }\end{array}$ & 9251 & ND & 2000 & Cell Signaling \\
\hline Rabbit anti-SAPK/JNK & 9252 & ND & 3000 & Cell Signaling \\
\hline $\begin{array}{l}\text { Rabbit anti-p-AMPK } \\
(\mathrm{T} 172)\end{array}$ & 2531 & ND & 2000 & Cell Signaling \\
\hline Rabbit anti-AMPK & 2532 & ND & 2000 & Cell Signaling \\
\hline Rabbit anti-LC3B & 2775 & ND & 3000 & Cell Signaling \\
\hline Rabbit anti-Cox2 & 160107 & ND & 2000 & $\begin{array}{l}\text { Cayman } \\
\text { Chemical }\end{array}$ \\
\hline Rabbit anti-EP2 & ab167171 & ND & 2000 & Abcam \\
\hline Rabbit anti-EP4 & sc-55596 & C-4 & 1000 & Santa Cruz \\
\hline Mouse anti- $\beta$-actin & sc-47778 & $\mathrm{C} 4$ & 5000 & Santa Cruz \\
\hline
\end{tabular}

\section{shRNAs}

The shRNAs were constructed using the pGFP-V-RS (TR30007) plasmid from OriGene Co. (Rockville, USA). Based on the results of prelimninary tests, the shRNAs exhibiting the most significant suppression effect to the target gene expression were used in this study. Sequences for shRNAs are as follows: AMPK: CTCCAAG ACCAGGAAGTCATACAATAGAA(Cat no: TG505729; Tube ID: GI 505440), EP2: AACTTCCTGTTCTACACAGTCAGA TGCCA(Cat no: TG516357; Tube ID: GI340313), EP4: TGGTGCTTCATCGACTGGACCACCAACGT(Cat no: TG516511; Tube ID: GI340311). TurboFect ${ }^{\mathrm{TM}}$ in vitro transfection reagent (Thermo Fisher Scientific, Waltham, USA) was used for transfection. After $24 \mathrm{~h}$ post transfection, cells were infected with BEFV at a multiplicity of infection (MOI) of 1 for further research purposes.

\section{Cell Viability Assay}

Cell viability was determined using the MTT assay to examine for the deleterious effects on cells by the compounds used in this study. MDBK cells were seeded in 4-well plates, grown for 1 day until about $60 \%$ confluence, and then treated with the compounds for $24 \mathrm{~h}$. Cells were swirled gently for a few seconds after $50 \mu \mathrm{l}$ of thiazolyl blue tetrazolium bromide (MTT; Sigma-Aldrich) was added to each well, and then cultured for $3 \mathrm{~h}$. After removing the medium, the cells were washed with PBS twice. $50 \mu \mathrm{l}$ of supernatant was evaluated at 570 $\mathrm{nm}$ for optical density, with subtraction of background at $670 \mathrm{~nm}$.

\section{Determination of Virus Titer}

To explore whether aspirin and AICAR inhibit viral growth, MDBK cells were pretreated with or without aspirin $(5 \mathrm{mM})$ or AICAR (1 mM), respectively, for $30 \mathrm{~min}$ and then infected with BEFV at an MOI of 1 for $18 \mathrm{~h}$. The effect of aspirin and AICAR on BEFV production was determined by virus titer. Virus titer was determined as described previously (7). Briefly, BEFVinfected MDBK cell supernatant was collected for determining virus titer by an agar overlay plaque assay carried out in triplicate. Cells in $6-\mathrm{cm}$ cell culture dishes were incubated for $1 \mathrm{~h}$ with diluted virus in $100 \mu \mathrm{l}$ serum-free MEM. The cells were then washed twice with MEM to remove unabsorbed viruses and overlaid with $2 \mathrm{ml}$ of $1 \%$ agarose in MEM which contains $5 \%$ FBS and antibiotics. Plaques were checked after an incubation period of 2 days at $37^{\circ} \mathrm{C}$ by staining with neutral red for $3 \mathrm{~h}$.

\section{Real-Time Quantitative Reverse Transcription and Polymerase Chain Reaction (qRT-PCR)}

To investigate whether aspirin and AICAR influence the transcription of the BEFV $\mathrm{M}$ gene as well as ATG-related genes of ULK1, Atg7, and LC3, MDCK cells were either drugstreated or infected with BEFV at an MOI of 1 . All cultures were collected and lysed at $18 \mathrm{~h}$ post infection (hpi). Total RNA was isolated from drug-treated or virus-infected cells using Trizol and Rneasy Mini Kit (QIAGEN) according to the manufacturer's protocols. Total RNAs were then subjected to a real-time qRTPCR as described previously (21). To obtain cDNAs from the RNA samples, reverse transcription was carried out at $42^{\circ} \mathrm{C}$ for 60 min with $2 \mu \mathrm{g}$ of total RNA, $4 \mu \mathrm{l}$ of $2.5 \mathrm{mM}$ dNTP, $500 \mathrm{ng}$ of oligo dT, $5 \mu \mathrm{l}$ of $5 \mathrm{X}$ RT buffer, and $1 \mu \mathrm{l}$ of M-MLV reverse transcriptase $(200 \mathrm{U} / \mu \mathrm{l})$ (Promega, Fitchburg, USA), and nuclease-free water in a total volume of $25 \mu \mathrm{l}$. Target cDNAs were further amplified with $\mathrm{iQ}^{\mathrm{TM}}$ SYBR Green Supermix (BioRad, Hercules, USA) with primers listed in Table 2. The reactions contained $0.25 \mu \mathrm{g}$ total cDNA, $0.5 \mu \mathrm{l}$ forward and reverse primers $(0.5 \mu \mathrm{M})$ each, $10 \mu \mathrm{l}$ of $\mathrm{iQ}^{\mathrm{TM}}$ SYBR Green Supermix, reagent and PCR grade water to a final volume of $20 \mu$ l. The PCR amplification programm was $95^{\circ} \mathrm{C}$ for $3 \mathrm{~min}, 35$ cycles of $95^{\circ} \mathrm{C}$ for $15 \mathrm{~s}$, and $56^{\circ} \mathrm{C}$ for $1 \mathrm{~min}$. Relative quantitation results were analysed with the CFX connect model of real time PCR detection system (Bio-Rad). The glyceraldehyde-3phosphate dehydrogenase (GAPDH) gene was used as an internal control for normalization.

\section{PGE2 Assay}

MDBK cells were infected with BEFV at an MOI of 1 and cultured for $18 \mathrm{~h}$. The medium was harvested, and the PGE2 
TABLE 2 | Primers used in this study for amplification of the respective targeted genes.

\begin{tabular}{|c|c|c|c|c|}
\hline Gene & Accession number & Sequence $\left(5^{\prime}-3^{\prime}\right)$ & Location & Expectedsize (bp) \\
\hline \multirow[t]{2}{*}{ BEFV M } & AF234533 & F: GAGATGGTTACCCTाTCAAGAAA GG & $1-23$ & 672 \\
\hline & & R: TCATGACTTAACTAAGTTAGTGAAACCATG & $672-643$ & \\
\hline \multirow[t]{2}{*}{ ULK1 } & NM_001205927 & F: AAGGGCAGCGCCAGCGAGG & $2605-2623$ & 490 \\
\hline & & R: CGTCCGCCTGGTCCGTGA & 3094-3077 & \\
\hline \multirow[t]{2}{*}{ ATG7 } & NM_001142967 & F: ATGGCCTITGAGGAACC $\Pi ा$ & $726-745$ & 210 \\
\hline & & R: ATGCCTCCCTTCTGGTTCTT & $935-916$ & \\
\hline \multirow[t]{2}{*}{ LC3B } & NM_001001169 & F: ATGCCGTCCGAGAAAACCTT & $1-20$ & 378 \\
\hline & & R: TTACACAGATAATTTCATTCC & $378-358$ & \\
\hline \multirow[t]{2}{*}{ GAPDH } & NM-001034034 & F: CAAGGTCATCCATGACAACTITG & $477-499$ & 496 \\
\hline & & R: GTCCACCACCCTGTTGCTGTAG & $972-951$ & \\
\hline
\end{tabular}

concentration in the culture medium of infected MDBK cells was determined using the Prostaglandin E2 EIA Kit (Cayman Chemical Co., Ann Arbor, USA).

\section{Isolation of Cytoplasmic and Nuclear Protein Fractions}

Cellular protein fractions were extracted through serial buffers in the CNM compartmental Protein Extraction Kit (Biochain Institute Inc., Hayward, USA). Cells were suspended in ice-cold buffer C then homogenized by passing through a syringe with a bent 26.5 gauge needle. The supernatant containing cytoplasmic proteins was collected and placed in another tube after centrifugation at 15,000 $\mathrm{g}$ at $4{ }^{\circ} \mathrm{C}$ for $20 \mathrm{~min}$. Cold buffer $\mathrm{W}$ was added to wash the pellet then removed after centrifugation at $15,000 \mathrm{~g}$ at $4^{\circ} \mathrm{C}$ for $20 \mathrm{~min}$. The pellet was resuspended with cold buffer, centrifuged at 15,000 $\mathrm{xg}$ at $4{ }^{\circ} \mathrm{C}$ for $20 \mathrm{~min}$, and the supernatant containing nuclear proteins was transferred to a clean tube.

\section{Plasmid Construction}

A pH-sensitive GFP-mCherry-LC3 reporter plasmid described previously (7) was used to observe the maturation of autolysosome from autophagosomes. GFP lost its fluorescence under a low $\mathrm{pH}$ environment when autophagosomes fuse with lysosomes to form autolysosomes. Thus, GFP-mCherry-LC3 could be a marker to detect autophagosome and autolysosomes.

\section{Transient Transfection}

For the transfection experiments, MDBK cells were seeded into six-well plates. At about $75 \%$ confluence, cells were transfected with the respective constructs using Turbofect reagent according to the manufacturer's instructions (Level Biotechnology Inc., New Taipei City, Taiwan).

\section{Electrophoresis and Western Blot}

Cells were lysed with Laemmli loading buffer (200 mM Tris, $\mathrm{pH}$ 6.8; $8 \%$ SDS, $10 \% \beta$-mercaptoethanol, $40 \%$ glycerol, $0.04 \%$ bromophenol blue) after washing with PBS twice. The cell lysates were collected and boiled for $10 \mathrm{~min}$. Samples were separated on $10 \%$ or $15 \%$ sodium dodecyl sulphatepolyacrylamide gel electrophoresis (SDS-PAGE) and then transferred to PVDF membranes. Protein expression was detected by using specific primary antibodies and a secondary antibody conjugated with horseradish peroxidase (HRP). The membranes were washed with TBST buffer $(50 \mathrm{mM}$ Tris- $\mathrm{HCl}$
pH7.5, $150 \mathrm{mM} \mathrm{NaCl}$, and $0.1 \%$ Tween 20), soaked with enhanced chemiluminescence solution (ECL plus) (Amersham Biosciences, Little Chalfont, Buckinghamshire, UK), and exposed to X-ray film. Protein band intensity was calculated using the program Photocapt (Vilber Lourmat, France). ImageJ was used to quantify Western blots signals.

\section{Immunofluorescence Staining}

MDBK cells expressing GFP-mCherry-LC3 or GFP-LC3 proteins described previously (7) were seeded on $18 \times 18 \mathrm{~mm}$ coverslips and cultured for $24 \mathrm{~h}$. The medium was replaced to 2\% FBS and the chemical agent of desire for $30 \mathrm{~min}$ before BEFV infection. Cells were infected with BEFV at an MOI of 1 and fixed with $4 \%$ paraformaldehyde in PBS for $1 \mathrm{~h}$ at room temperature, followed by soaking in PBS with $0.3 \%$ Triton X-100 for 10 min. After washing with PBS, the cells were blocked with SuperBlock ${ }^{\circledR}$ T20 (PBS) blocking buffer (Thermo Fisher Scientific, Waltham, USA) at $4^{\circ} \mathrm{C}$ for $30 \mathrm{~min}$. Cell nuclei were stained with 4', 6-diamidino2-phenylindole (DAPI) for $10 \mathrm{~min}$ in the dark, followed by observation with a BX51 fluorescence microscope (Olympus, Tokyo, Japan). The coverslips were washed with PBS three times at room temperature and then mounted onto glass slides using ibidi mounting medium (ibidi GmbH, Lochhamer Schlag, Germany). The LC3 punta images were observed under fluorescence microscopy and the montage was edited using Adobe Photoshop CC.

\section{Statistical Analysis}

All data obtained in this study were evaluated for statistical significance according to student t-test or the Duncan's multiple range test (DMRT) using SPSS software (version 20.0). P values that were less than 0.05 were considered statistically significant (22).

\section{RESULTS}

\section{Aspirin and AICAR Transcriptionally Downregulate the BEFV M Gene and Inhibit Virus Replication}

As reported previously, we found that Cox-2 and PGE2 are important in BEFV entry and subsequent replication (12). More recently, we demonstrated that BEFV-induced autophagy enhancing virus replication via upregulation of the Src/JNK/AP1 and PI3K/Akt/NF-KB pathways and suppression of the PI3K/Akt/ 
mTOR pathway (7). In this study, we further exploreed whether aspirin and AICAR affect Cox-2 and the signaling pathways, which are involved in virus entry and induction of autophagy. The concentrations that produced a 50\% inhibitory effect (IC50) of aspirin and AICAR have been shown previously $(23,24)$. MDBK cells were infected with BEFV at an MOI of 1 for $18 \mathrm{~h}$ with or without pretreatment of two comcentions of aspirin and AICAR, respectively. In this work,virus yield was significantly reduced in aspirin- and AICAR-treated MDBK cells (Figure 1A), suggesting that these drugs have a potential anti-viral ability. To examine whether all compounds used in this study had the deleterious effects on MDBK cells, cell viability was determined using the MTT assay. As shown in Figure 1B, cell viability was slighly reduced compared to the cases with mock treatments. Recently, we have shown that the BEFV M protein is one of major protein that is involved in BEFV-induced autophagy (7). Thus, the levels of the BEFV $M$ protein were also analyzed in aspirin- and AICARtreated MDBK cells. Our results reveal tha both aspirin and
AICAR reduced the levels of BEFV $M$ protein (Figure 1C). Furthermore, in the presence of proteasome inhibitor MG132, the decreased level of $M$ protein was not reversed in aspirin- and AICAR-treated MDBK cells (Figure 1D), suggesting that these drugs reeduce the level of the BEFV $M$ protein is independent of the proteaseome pathway. To further examine whether aspirin or AICAR transcriptionally downregulate the BEFV $M$, the $M$ mRNA levels in aspirin- and AICAR-treated MDBK cells were examined. As shown in Figure 1E, the M mRNA levels in aspirinand AICAR-treated MDBK cells were reduced as comparsion to those in untreated cells, suggesting that the BEFV $M$ is transcriptionally downregulated by aspirin and AICAR.

\section{Cox-2 Is Essential for BEFV-Induced Autophagy}

We have shown previously that BEFV up-regulates the expression of Cox-2 in a time-dependent manner (12). Cox-1 and Cox-2 are two isozymes of cyclooxygenase which are
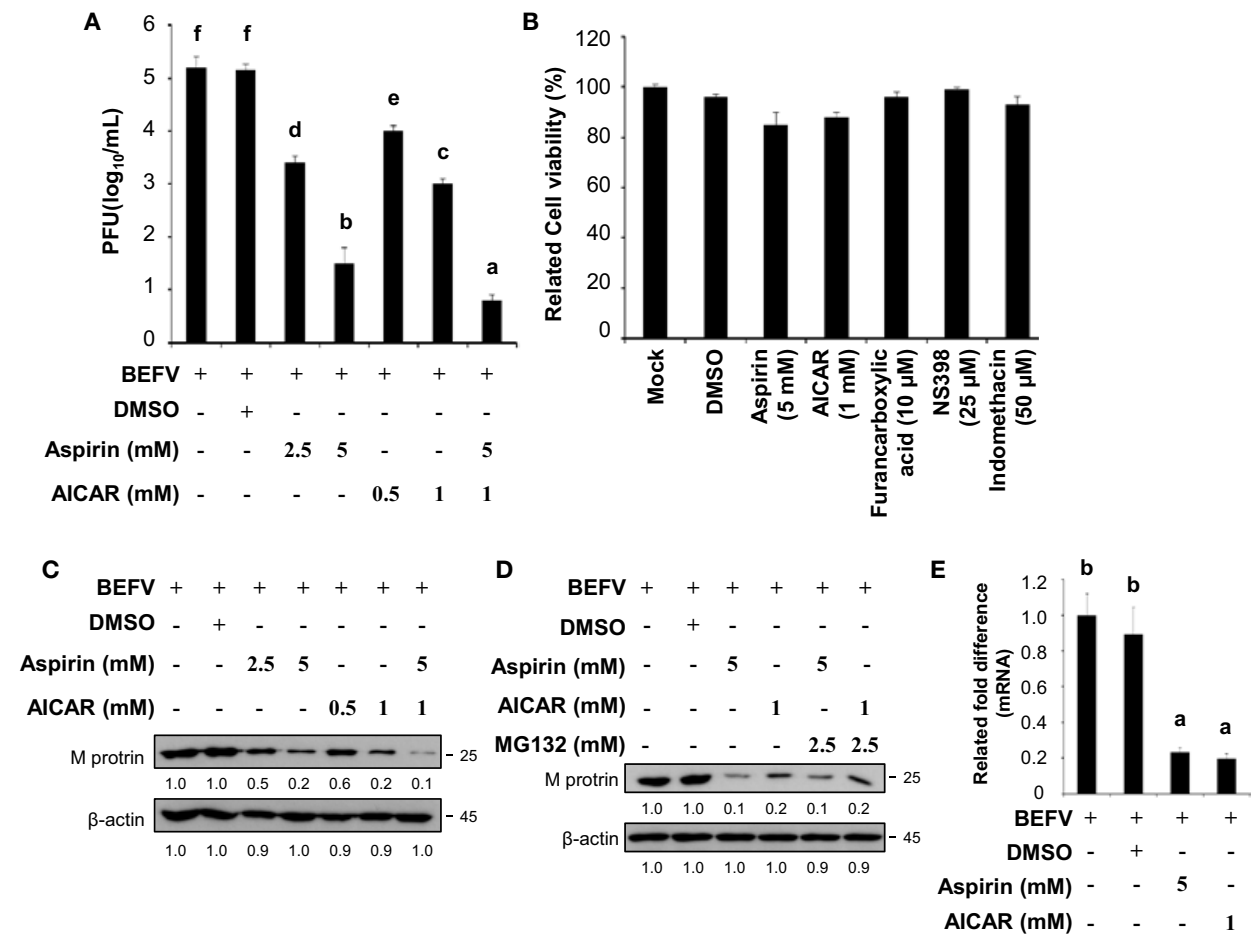

FIGURE 1 | Aspirin and 5-aminoimidazole-4-carboxamide-1- $\beta$-riboside (AICAR) inhibit viral growth. (A) Madin-Darby bovine kidney (MDBK) cells were pretreated with or without aspirin (2.5 and $5 \mathrm{mM}$ ) or AICAR (0.5 and $1 \mathrm{mM})$, respectively, for 30 min and then infected with BEFV at an MOI of 1 for $18 \mathrm{~h}$. The effect of aspirin and AICAR on BEFV production was determined. Significance between the treatments was determined by Duncan's Multiple Range Test (MDRT) using SPSS software (Version 20.0). Means with common alphabets ( $, \mathrm{b}, \mathrm{c}, \mathrm{d}, \mathrm{e}, \mathrm{f}$ ) denotes no significance at $\mathrm{p}<0.05$. Each value represents mean \pm SE of three independent experiments. (B) To examine whether the compounds used in this study had the deleterious effects on cells, cell viability was determined using the MTT assay. Each value represents mean \pm SE of three independent experiments. (C, D) The levels of the BEFV M protein in aspirin- and AICAR-treated MDBK cells were examined (C) in the presence or absence of proteasome inhibitor MG132 (D). The levels of indicated proteins in the BEFV-infected group were considered onefold. The inactivation folds indicated below each lane were normalized against values for the BEFV-infected group. Protein levels were normalized to those for $\beta$-actin. Signals in all Western blots were quantified with ImageJ software. All experiments were conducted in three independent experiments. (E) The BEFV M and GADPH mRNA levels were quantified by real-time QRT-PCR in BEFV-infected MDBK cells in the presence or absence of indicated drugs. In real-time qRT-PCR amplification of the $\mathrm{M}$ and GADPH genes, MDBK cells were infected with BEFV at an MOI of 1. The BEFV-infected cells were collected at either 24 hpi, and total RNAs were extracted for real-time qRT-PCR. Significance between the treatments was determined by Duncan's Multiple Range Test (MDRT) using SPSS software (Version 20.0). Means with common alphabets $(a, b)$ denotes no significance at $p<0.05$. Each value represents mean \pm SE of three independent experiments. 
encoded by individual genes and exert functional differences (25). It is interesting to study the roles of each after BEFV entry. As illustrated in Figure 2A, the levels of Cox-2 and LC3-II increased in BEFV-infected MDBK cells. Selective inhibition of the activity of Cox-2 by NS398 (26) reduced the levels of the BEFV $M$ protein and LC3-II while the Cox-2 level increased (Figure 2A). Our results were consistent with previous studies that suggest NS-398 blocks Cox-2 activity but upregulates Cox-2 (27-29). Indomethacin is one of the NSAIDs, which nonselectively inhibits cyclooxygenase activity but is more potent against Cox-1 than Cox-2 (30). A concomitant decreased expression level of Cox-2 by indomethacin was also reported (31-33). Although an increased level of Cox-2 induced by BEFV was notably reduced by indomethacin, the decrease in the levels of the BEFV $\mathrm{M}$ protein and LC3-II were less pronounced as compared to NS398 (Figure 2A). Collectively, our findings reveal that inhibition of Cox-2 reduces the levels of the BEFV M protein and LC3-II.

\section{Suppression of BEFV-Induced Autophagy by AICAR Is Independent of AMPK}

AMPK is a serine-threonine kinase up-regulated by various stimuli through sensing an elevated intracellular AMP/ATP ratio. AMPK signaling is involved in multiple metabolic reprogramming and cell growth as well as autophagy. Accordingly, we investigated the role of AMPK in BEFVinduced autophagy. The effect of AMPK on BEFV was examined by measuring the expression level of the BEFV $\mathrm{M}$ protein. As shown in Figure 2A, the increased levels of Cox-2 and LC3-II were seen in BEFV-infected MDBK cells. Activation of AMPK by an AMPK activator, furancarboxylic acid, increased the phosphorylated forms of AMPK (p-AMPK) and Cox-2 level in BEFV-infected cells (Figure 2A). Interestingly, elevated levels of Cox-2 and LC3-II in BEFV-infected or furancarboxylic acid pre-treated groups were not altered in AMPK-knockdown cells (Figure 2B). Collectively, these data reveal that BEFV-induced autophagy is not regulated by AMPK signaling. In contrast, AICAR as an AMPK activator reduced the levels of BEFV M protein, Cox-2, LC3-II in BEFV-infected cells, and AMPKknockdown cells (Figure 2B). Our finding suggests that AICAR inhibits BEFV-induced autophagy through an AMPKindependent mechanism.

\section{Aspirin and AICAR-Mediated Inhibition of BEFV-Activated Prostaglandin E2 (PGE2) and G-Protein-Coupled E-Prostanoid Receptors 2 (EP2)}

Our earlier study has shown that BEFV activates the Src/JNK/ $\mathrm{AP} 1$ and $\mathrm{PI} 3 \mathrm{~K} / \mathrm{Akt} / \mathrm{NF}-\kappa \mathrm{B}$ pathways to induce Cox-2-mediated production of intracellular PGE2 at the stage of virus entry (12). PGE2 interacts with EP2 and EP4, further enhancing the Src/ JNK/AP1 and PI3K/Akt/NF- $\kappa B$ pathways in an autocrine or paracrine fashion to increase virus entry (12). More recently, we also found that BEFV triggers autophagy via activation of the Src/JNK/AP1 pathway (7). The crosstalk between PGE2 and autophagy induction and the potential role of EP-mediated signaling in BEFV-induced autophagy were further investigated. In this work, MDBK cells were infected with BEFV at an MOI of 1 for $18 \mathrm{~h}$, with or without pretreatment of AICAR or aspirin, respectively. As shown in Figure 3A, BEFV-induced accumulation

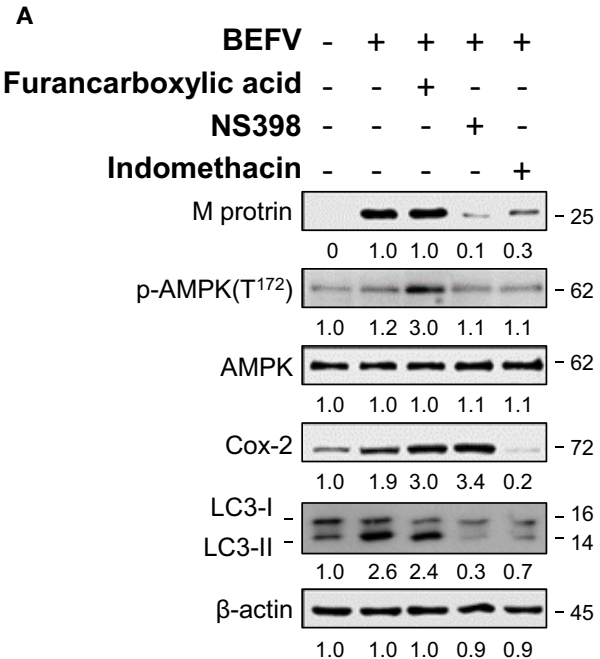

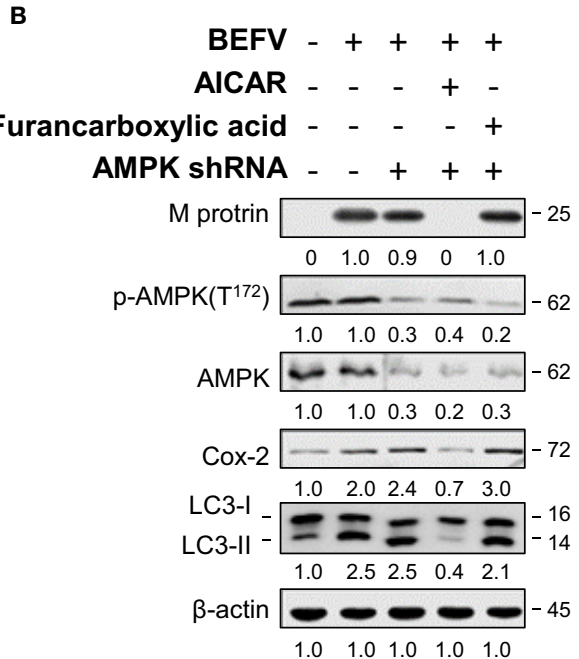

FIGURE 2 | BEFV-induced autophagy requires Cox-2 and is AMPK-independent. (A) MDBK cells were pretreated either with Furancarboxylic acid, NS-398 (25 $\mu$ M) and indomethacin for $1 \mathrm{~h}$ followed by infection with BEFV at an MOI of 1 for $18 \mathrm{~h}$. (B) MDBK cells were transfected with AMPK shRNA for $6 \mathrm{~h}$, then with or without pretreatment of Furancarboxylic acid or AICAR for $1 \mathrm{~h}$, followed by infection with BEFV at an MOI of 1 . The cell lysates were harvested at $18 \mathrm{hpi}$ and subjected to immunoblotting using antibodies as indicated. The levels of indicated proteins in the mock group were considered onefold. The activation and inactivation folds indicated below each lane were normalized against values for the mock control group. Protein levels were normalized to those for $\beta$-actin. Signals in all Western blots were quantified with ImageJ software. All experiments were conducted in three independent experiments. The predicted size of each protein was labeled at the righthand side in $\mathrm{kDa}$. 


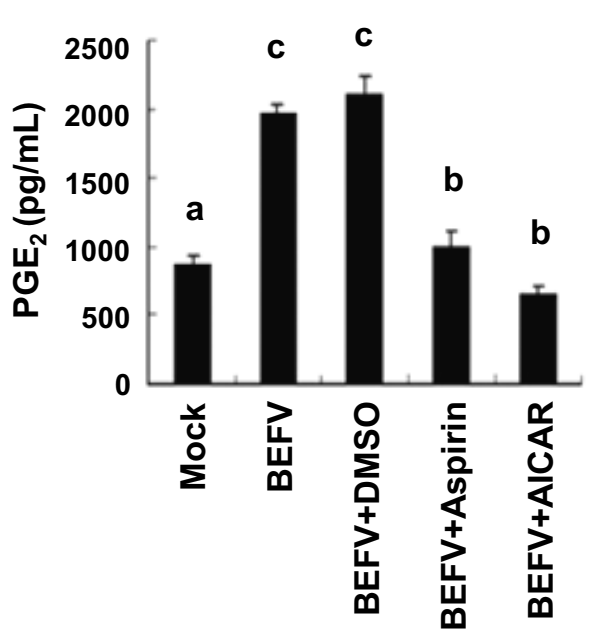

B

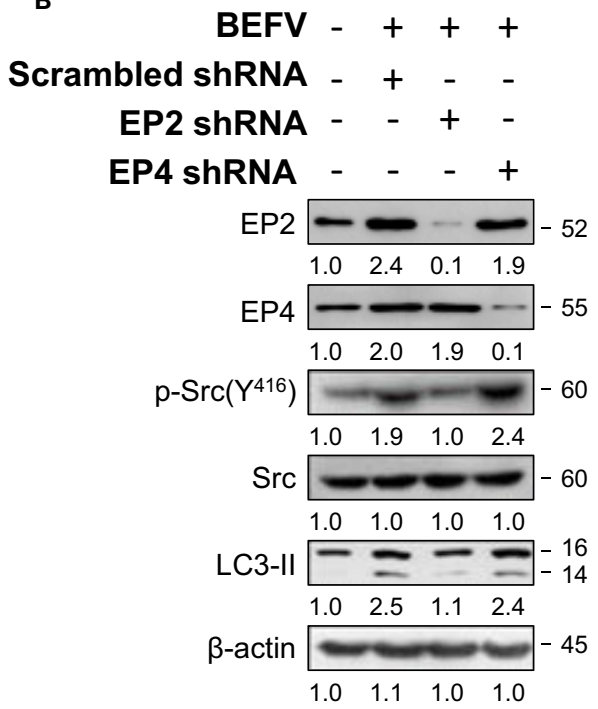

FIGURE 3 | BEFV triggers the PGE2/EP receptor pathway. (A) MDBK cells were pretreated with or without aspirin (5 mM) or AICAR (1 mM), respectively, for 30 min and then infected with BEFV at an MOI of 1 for $18 \mathrm{~h}$. Supernatants of BEFV-infected cells were harvested for quantification of PGE2 measured by enzyme linked immunosorbent assay (ELISA). Significance between the treatments was determined by Duncan's Multiple Range Test (MDRT) using SPSS software (Version 20.0). Means with common alphabets ( $\mathrm{a}, \mathrm{b}, \mathrm{c})$ denotes no significance at $\mathrm{p}<0.05$. Each value represents mean $\pm \mathrm{SE}$ of three independent experiments. (B) MDBK cells were transfected with scrambled (negative control), EP2, and EP4 shRNAs, respectively, for $24 \mathrm{~h}$, followed by infection with BEFV at an MOI of 1 for 18 h. The effect of E-prostanoids (EPS) on BEFV-induced LC3 II was analyzed by immunoblotting. The levels of indicated proteins in the mock group were considered onefold. The activation and inactivation folds indicated below each lane were normalized against values for the mock control group. $\beta$-actin was used for the internal control for normalization. Signals in all Western blots were quantified with ImageJ software. All experiments were conducted in three independent experiments. The predicted size of each protein was labeled at the right-hand side in $\mathrm{kDa}$.

of PGE2 was observed. Both aspirin and AICAR reduced the concentrations of PGE2 elevated by BEFV. We next analyzed the effect of EPs on BEFV-induced autophagy. We found that knockdown of EP2 via a specific shRNA reversed the increased levels of p-Src and LC3-II by BEFV while there is no obvious inhibitory effect on EP4 knockdown cells (Figure 3B). These results suggested that activation of a PGE2/EP2 signal to amplify the Src/ JNK/AP1 pathway is important for BEFV to induce autophagy.

\section{Reversion of the BEFV-Activated PI3K/Akt/ NF- $\mathrm{KB}$ and Src/JNK/AP1 Pathways as Well as the BEFV-Anactivated PI3K/Akt/mTOR Pathway by AICAR}

Having shown that AICAR inhibits BEFV-induced autophagy through an AMPK-independent manner. We next wanted to explore the mechanisms of AICAR on suppression of BEFVinduced autophagy. As shown in Figure 4A, the BEFV-induced increased levels of the phosphorylated form of PI3Kp85 (Y458), Akt (T308 and S473), Src (Y416), and JNK(T183/T185) were reversed by AICAR in a dose-dependent manner. BEFVmodulated inhibition of I $\mathrm{B} \alpha$ and nuclear translocation of NF$\kappa B$ subunits ( $\mathrm{p} 50$ and $\mathrm{p} 65$ ) were simultaneously reversed by AICAR in a dose-dependent manner (Figure 4B). These results suggest that the PI3K/Akt/NF- $\mathrm{KB}$ and Src/JNK/AP1 pathways activated at an early stage of BEFV infection were reversed by
AICAR. At the late stage of BEFV infection, the expression level of the BEFV $M$ protein was dramatically reduced in AICARtreated cells (Figure 5A). Recently, we showed that the BEFV M protein suppresses the PI3K/Akt/mTORC1 pathway to enhance BEFV-induced autophagy (7). In the current study, BEFVinduced decreased levels of p-PI3Kp85 and p-Akt along with p-mTOR were not further suppressed but were increased by AICAR treatment (Figure 5A). All of these reversions induced by AICAR were dose-dependent (Figures 4A, B, 5A).

Having demonstrated that multiple pathways regulated by BEFV were reversed by AICAR, we further investigated the effect of AICAR to Atg-related protein expression in BEFV-infected cells. Autophagy consists of several sequential steps including induction, autophagosome formation, degradation and reuse (34). Class III phosphatidylinositol 3-kinase complex I (PI3KC3-C1) and the ULK1 complex are two major initiation complexes involving in commencement of autophagy. Beclin 1 is a constituent of the PI3KC3-C1 complex, and $\mathrm{Bcl}-2$ binds to Beclin 1 to inhibit autophagy (35). Phosphorylation of Bcl-2 to dissociate Beclin 1 can be induced by activating JNK to initiate autophagy (36). We have shown that BEFV increases JNKmediated phosphorylation of Bcl-2 and the level of Cox-2 for autophagy (7). The present study reveals that increased levels of Bcl-2 phosphorylation induced by the Src-JNK pathway and the increased level of Cox-2 induced by BEFV were reversed by AICAR (Figure 5A). Phosphorylation of Beclin 1 by ULK1 is 


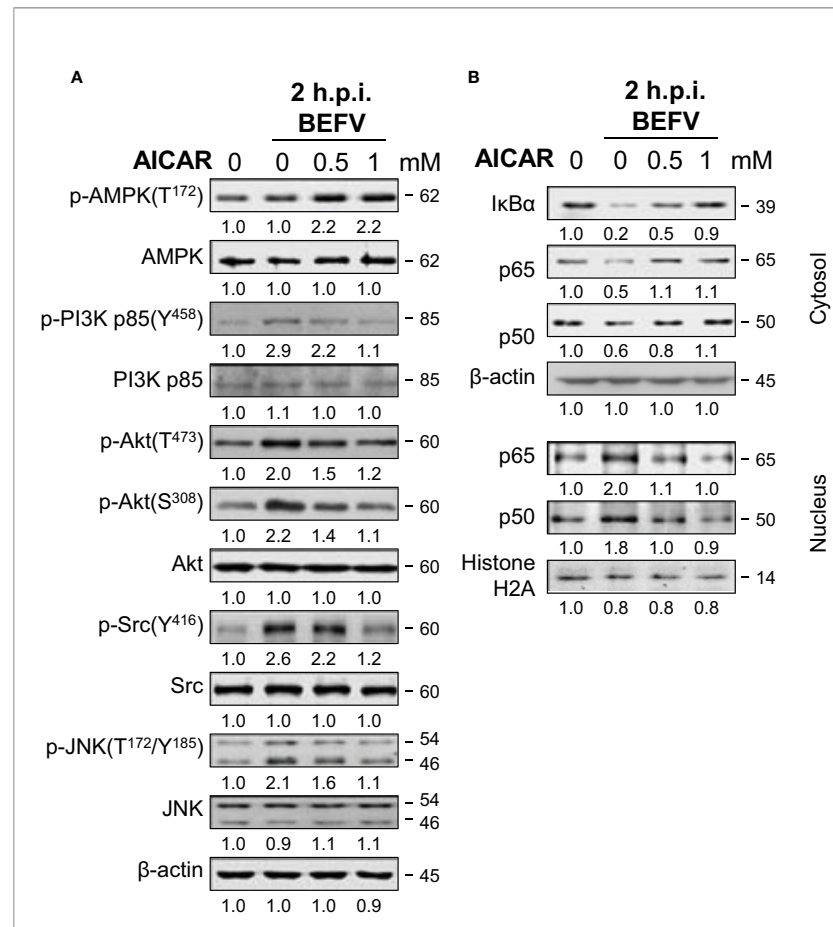

FIGURE 4 | BEFV activates the PI3K/AKt/NF- KB and Src/JNK/AP-1 pathways in the early stage and is suppressed by 5-aminoimidazole-4carboxamide-1- $\beta$-riboside (AICAR). MDBK cells were pretreated with or without AICAR (0.5 and $1 \mathrm{mM}$ ), respectively, for $30 \mathrm{~min}$, followed by infection with BEFV at an $\mathrm{MOI}$ of 1 for $2 \mathrm{~h}$. (A) The cell lysate or (B) cytosolic and nuclear fraction were collected and subjected to immunoblotting with the respective antibodies as indicated. The levels of indicated proteins in the mock group were considered onefold. The activation and inactivation folds indicated below each lane were normalized against values for the mock control group. $\beta$-actin was used for the internal control for

normalization.Signals in all Western blots were quantified with ImageJ software. All experiments were conducted in three independent experiments. The predicted size of each protein was labeled at the right-hand side in kDa.

required for full autophagy induction (36). Suppression of the PI3K/Akt signal decreases phosphorylation of mTOR at Ser ${ }^{2448}$ and results in inactivation of $\mathrm{mTOR}$, which hence loses its ability to control ULK1 by phosphorylation at site $S^{757}$ so as to activate ULK1. As illustrated in Figure 5A, BEFV suppressed the PI3K/ Akt/mTOR pathway to reduce phosphorylation of ULK1 $\left(S^{757}\right)$, but AICAR did not reverse this and the level of p-ULK1 was even further decreased (Figure 5A). We also observed that AICAR decreases the level of Atg-related proteins including ULK1, Atg7, and Beclin 1 (Figure 5A). To investigate the precise mechanism of AICAR on these ATG-related proteins, real-time qRT-PCR was carried out. Data presented in Figure 5B demonstrate a suppression effect of AICAR on mRNA expression of the ULK1 and LC3 genes except for Atg7, suggesting that AICAR transcriptionally downregultes ULK1 and LC3. Furthermore, co-treatment of AICAR with MG132 counteracted the effect of AICAR on the reduction of Atg7 levels (Figure 5C), suggesting that AICAR enhances Atg7 degradation by the proteasome pathway. Collectively, our results reveal that AICAR suppresses
BEF-induced autophagy via suppression of ATG-related proteins of ULK1, Atg7, and LC3.

\section{Reversion of the BEFV-Activated PI3K/Akt/ NF- $\kappa B$ and Src/JNK/AP1 Pathways in the Early Stage of Infection and the BEFV- Suppressed PI3K/Akt/mTOR Pathway in the Late Stage of Infection by Aspirin}

Having shown that aspirin significantly inhibites virus yield (Figure 1A), we next wanted to explore the precise mechanism of the suppression effect of aspirin on BEFV replication. MDBK cells were pretreated with or without aspirin $(5 \mathrm{mM})$ for $30 \mathrm{~min}$ followed by infection with BEFV at an MOI of 1 . Cell lysates were collected and immunoblotted with the respective antibodies. As illustrated in Figure $\mathbf{6 A}$, at the early stage of BEFV infection, increased levels of $\mathrm{p}$-Src and p-JNK induced by BEFV were moderately reversed by aspirin while increased levels of $\mathrm{p}$-PI3K and $\mathrm{p}$-Akt induced by BEFV were only slightly reversed by aspirin (Figure 6A). However, degradation of $\mathrm{I} \kappa \mathrm{B} \alpha$ and nuclear translocation of NF- $\kappa B$ subunits (p50 and p65) were reversed by aspirin (Figure 6A). At the late stage of BEFV infection, the decreased levels of p-PI3Kp85, p-Akt, p-mTOR, and p-ULK1 were detected and reversed by aspirin while increased levels of $\mathrm{p}-\mathrm{Src}$ and $\mathrm{p}$-JNK induced by BEFV were not reversed by aspirin (Figure 6C). Similar to AICAR treatment, the expression level of the BEFV $M$ protein was dramatically reduced in aspirin-treated cells at the late stage of BEFV infection (Figures 6B, C). The BEFV-induced increased level of LC3-II was dramatically reversed by aspirin. In contrast to AICAR, the levels of Atg7, Beclin 1, and ULK were not affected in aspirin-treated cells (Figures 5A, 6B). Collectively, these results show that aspirin reverses $\mathrm{BEFV}$-mediated degradation of $\mathrm{I} \kappa \mathrm{B} \alpha$, upregulates $\mathrm{PI} 3 \mathrm{~K} / \mathrm{Akt} / \mathrm{NF}-\kappa \mathrm{B}$ and $\mathrm{Src} /$ JNK/AP1 pathways in the early stage of infection, and downregulates the PI3K/Akt/mTOR pathway in the late stage of infection. Our findings suggest that aspirin inhibits BEFV-induced autophagy, thereby inhibiting virus propagation.

\section{Reversion of Autophagy Flux Delayed by BEFV by Aspirin and AICAR}

The final process of autophagy is degradation and reused by fusion of autophagosomes with lysosomes to form autolysosomes. Our recent report showed that autophagic flux was delayed during BEFV infection (7). It is interesting to investigate whether aspirin or AICAR affect the autophagic flux. BEFV-infected MDBK cells were pretreated with or without AICAR ( $1 \mathrm{mM})$ and aspirin $(5 \mathrm{mM})$, respectively. Cell lysates were collected at the indicated time points and the levels of $\mathrm{M}$ protein and autophagic protein markers including p62 and LC3-II were analyzed. p62 is a multifunctional protein and serves as an autophagic flux reporter and integration center for the autophagosome and ubiquitin-proteasome system (37). It interacts with LC3-II and is selectively degraded by the autophage-lysosome pathway. As shown in Figure 7A, the increased level of p62 was further increased at $12 \mathrm{hpi}$ and then 

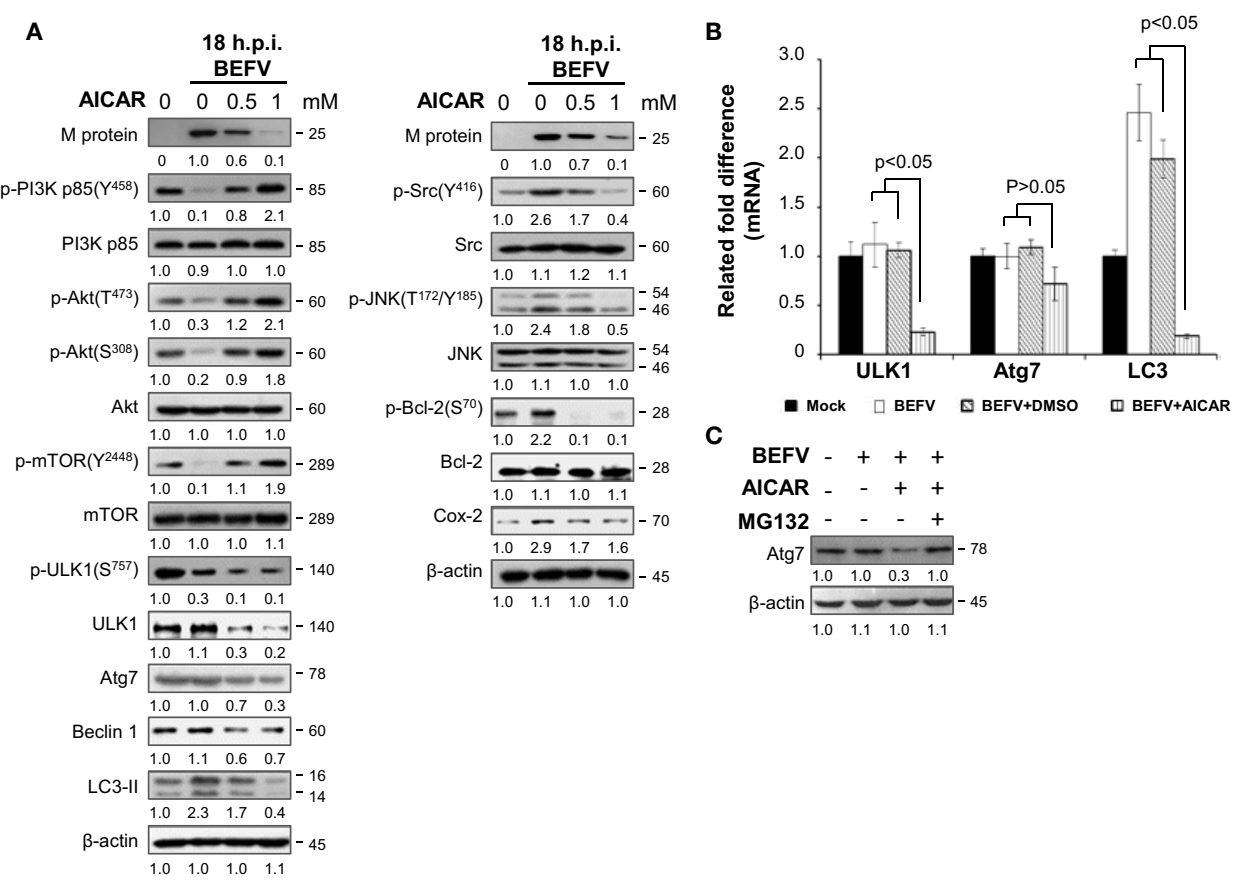

FIGURE 5 | BEFV induces downregulation of the PI3K/Akt/mTOR pathway and autophagy in the late stage, suppressed by 5-aminoimidazole-4-carboxamide-1- $\beta$ riboside (AICAR). (A) MDBK cells were pretreated with or without AICAR (0.5 and $1 \mathrm{mM})$, respectively, for 30 min, followed by infection with BEFV at an MOI of 1 for $18 \mathrm{~h}$. The cell lysate was collected and subjected to immunoblotting with the respective antibodies as indicated. (B) Total cellular RNA of BEFV-infected MDBK cells was extracted, transcribed into CDNA, and subjected to real-time qRT-PCR. The mRNA levels of ULK1, Atg7, and LC3 were normalized to that of GAPDH. The mRNA levels in mock-treated cells was considered 100\%. All data obtained in this study were analyzed by student t-test and expressed as averages of three independent experiments. $\mathrm{P}$ values of less than 0.05 were considered significant. (C) MDBK cells were pretreated with AICAR alone or in combination with MG132 $(5 \mathrm{mM})$ for $30 \mathrm{~min}$, followed by infection with BEFV at an $\mathrm{MOI}$ of 1 for $18 \mathrm{~h}$. Cell lysates were collected and subjected to immunoblotting with the antibody specific to Atg7. The levels of indicated proteins in the mock group $(\mathbf{A}, \mathbf{C})$ were considered onefold. The activation and inactivation folds indicated below each lane were normalized against values for the mock control group. Protein levels were normalized to those for $\beta$-actin. Signals in all Western blots were quantified with ImageJ software. All experiments were conducted in three independent experiments. The predicted size of each protein was labeled at the right-hand side in $\mathrm{kDa}$.

decreased at 24 hpi., suggesting that BEFV protects p62 from degradation via an unknown mechanism before completing virus replication. The increased level of lipid conjugated LC3-II by BEFV became evident at $18 \mathrm{hpi}$. and then decreased at $24 \mathrm{hpi}$. The expression level of $\mathrm{M}$ protein was decreased in AICAR- or aspirin-treated MDBK cells as compared to BEFV infection alone (Figure 7A). This is consistent with the data shown in Figure 1. Pretreatment with AICAR or aspirin, respectively, inhibited the accumulation of p62 or LC3-II induced by BEFV (Figure 7A). To further confirm this observation, we used a $\mathrm{pH}-$ sensitive GFP-mCherry-LC3 reporter plasmid to examine the maturation process of autophagosomes. GFP-LC3 is unstable in the lysosomal acidic and degradative conditions, while mCherryLC3 is relative stable (7). After 18 hpi., the puncta of cells pretreated with AICAR or aspirin were significantly reduced (Figure 7B), suggesting that autophagosome formation was inhibited by aspirin and AICAR. The count of GFP-mCherryLC3 puncta was significantly diminished in drug pretreated cells as compared to BEFV-infected cells (Figure 7C). These results indicate that delayed autophagy flux induced by BEFV was inhibited by aspirin or AICAR.

\section{DISCUSSION}

The present study provides a promising approach to inhibit BEFV replication for therapeutic purposes. We demonstrate for the first time that AICAR and aspirin attenuate BEFV replication by inhibiting BEFV-induced autophagy via suppression of the BEFV-activated PI3K/Akt/NF- $\mathrm{KB}$ and Src/JNK pathways and reversion of the BEFV-suppressed PI3K/Akt/mTOR pathway. Our results also reveal that aspirin and AICAR negatively regulate the $\mathrm{BEFV} M$ protein, which is one of the major protein for BEFV-indiced autophagy (7). Autophagy is the cellular catabolic process in which cytoplasmic target material is transported to lysosomes for degradation via phagosomes, which are a double-membrane vacuoles (38). This is a selfdegradative process in response to nutrient stress or balancing sources of energy at critical conditions (39) and acts as a cellintrinsic anti-viral immune defense (40). Autophagy plays a role in immunological processes to direct elimination of microbes, control inflammation, and also plays a role in antigen presentation, lymphocyte homeostasis, and secretion of immune mediators (41). Although viruses can be eliminated 
A
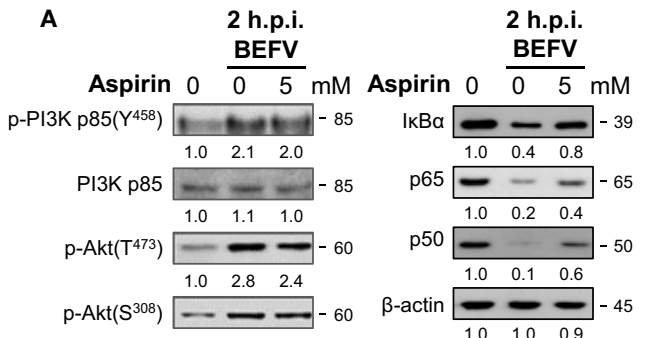

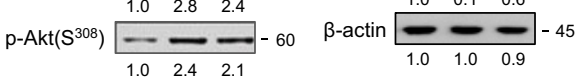

Akt $\begin{array}{lll}1.0 & 1.2 & 1.1\end{array}$

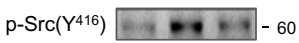

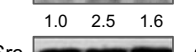

Src $\longrightarrow$

$\begin{array}{lll}1.0 & 1.0 & 1.2\end{array}$

$\mathrm{p}-J N K\left(\mathrm{~T}^{172} / \mathrm{Y}^{185}\right) \square-54$

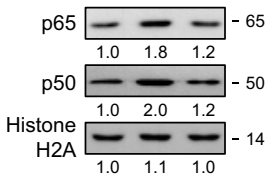

$\mathrm{JNK} \equiv-54$

$\begin{array}{lll}1.0 & 1.2 & 1.1\end{array}$

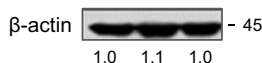

C 18 h.p.i.

BEFV

Aspirin $0 \longdiv { 0 5 } \mathrm { mM }$

M protein -25

$$
\begin{array}{lll}
0 & 1.0 & 0.1 \\
\hline
\end{array}
$$

$\mathrm{P}-\mathrm{Src}\left(\mathrm{Y}^{416}\right) \longrightarrow-60$

\begin{tabular}{lll}
1.0 & 2.8 & 2.9 \\
\hline & &
\end{tabular}

$\mathrm{Src}=-60$

p-JNK $1.0 \quad 1.0 \quad 1.0$

$\begin{array}{r}\mathrm{p}-\mathrm{JNK} \\ \left(\mathrm{T}^{172} / \mathrm{Y}^{185}\right)\end{array}=-54$

JNK $=2.6 \quad 2.4-54$

$\begin{array}{lll}1.0 & 1.0 & 1.0\end{array}$

$\beta$-actin \begin{tabular}{lll}
1.0 & $1.0 \quad 1.0$ \\
\hline
\end{tabular}

$\begin{array}{lll}1.0 & 1.0 & 1.0\end{array}$

$\frac{\infty}{\frac{\omega}{0}}$

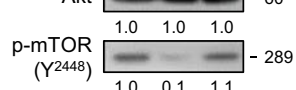

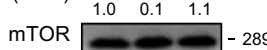

$$
\begin{array}{lll}
\hline 1.0 & 1.0 & 1.0 \\
\hline
\end{array}
$$

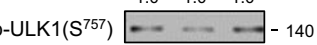

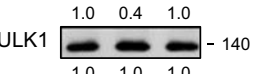

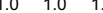

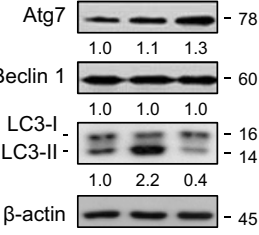

FIGURE 6 | Aspirin suppresses the BEFV-activated Src/JNK/AP-1 pathway at the early stage and reverses the BEFV-inactivated PI3K/Akt/mTOR pathway at late stage. MDBK cells were pretreated with or without aspirin $(5 \mathrm{mM})$, respectively for $30 \mathrm{~min}$, followed by infection with BEFV at an $\mathrm{MOI}$ of 1 for $2 \mathrm{hpi}$ (A) and $18 \mathrm{hpi}$ (B, C). The cell lysates or cytosolic and nuclear fraction were collected at the indicated time points and subjected to immunoblotting with the respective antibodies. The levels of indicated proteins in the mock control group were considered onefold. The activation and inactivation folds indicated below each lane were normalized against values for the mock control group. Protein levels were normalized to those for $\beta$-actin. Signals in all Western blots were quantified with ImageJ software. All experiments were conducted in three independent experiments. The predicted size of each protein was labeled at the right-hand side in $\mathrm{kDa}$.

through the innate immune response and selective degradation of immune components with viral particles by autophagy, viruses develop diverse strategies such as evasion of autophagic degradation, manipulation of autophagosomes, regulation of lipophagy, and exocytosis to hijack and subvert autophagy for their replication (42-46). Autophagy can be induced by suppression of $\mathrm{mTOR}$ or activation of AMPK. Our recent study demonstrated that BEFV triggers autophagy to beneft its replication through suppression of the PI3K/Akt/mTOR pathway (12). AMPK serves as a double-edged sword to viruses and its activation is essential for some viruses. For example, the 17 protein of avian reovirus activates AMPK to induce autophagy for replication (42), Bluetongue virus induces autophagy through activation of AMPK to sustain viral replication (47), and respiratory syncytial virus induces autophagy through ROS and AMPK activation, which is beneficial for viral replication (48). On the other hand, activation of AMPK is lethal to certain viruses such as hepatitis C virus (HCV) (49), Epstein-Barr virus (50), and herpes simplex virus (51). AICAR is a common AMPK activator. Several studies suggested that AICAR activates AMPK activity, resulting in inhibition of HCV (52), herpes simplex virus type 1 (53), Coxsackievirus B3 (54), Kaposi's sarcoma-associated herpes virus (55), and hepatitis B virus (HBV) (56). In the current study, AICAR suppresses BEFV replication by inhibiting autophagy. However, autophagy induced by BEFV is AMPK independent. Our findings presented in this work revealed that AICAR inhibits BEFV-induced autophagy is in an AMPKindependent manner. AICAR does not directly activate AMPK but is metabolized to a direct activator, ZMP (57). ZMP as an AMP mimetic is an intermediate for de novo purine biosynthesis of inosine monophosphate (IMP) (20). ZMP binds to and activates a riboswitch to directly regulate the expression of one-carbon metabolism genes in multiple bacterial lineages (22), and is regarded as a master regulator of one-carbon metabolism (58). It should be taken into account that AICAR is able to activate many other AMP-dependent enzymes, such as fructose-1, 6-bisphosphatase (59). Several studies have shown that cellular metabolism regulated by AICAR is AMPKindependent, including apoptosis induction in Jurkat cells (60), inhibition of glucose phosphorylation in rat hepatocytes (61), induction of nuclear translocation of Nrf2 in hepatocytes (62), suppression of LPS-induced iNOS \& Cox-2 mRNA/protein (63), decreased transcription of NF- $\mathrm{KB}$-dependent genes (23), and inhibitory inflammatory responses in macrophages (64).

Prostaglandin E2 is prostanoid that was first discovered in 1964 (65). Synthesis of prostanoids through eicosanoid metabolism is initiated from hydrolysis of plasma membrane 


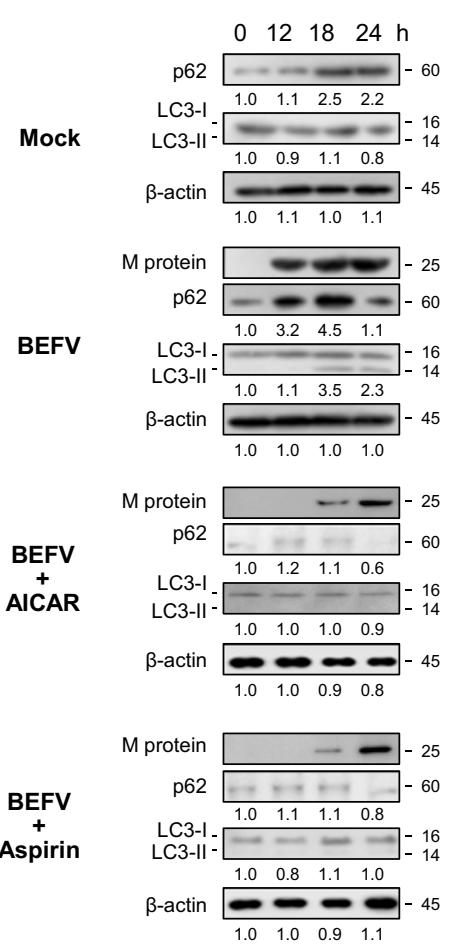

B
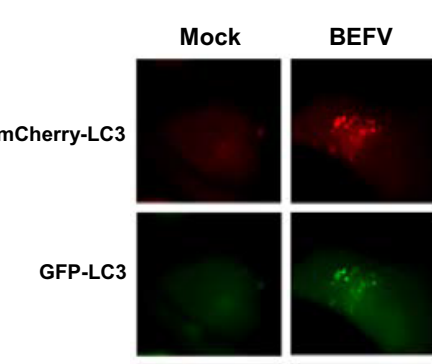

BEFV
+
AICAR
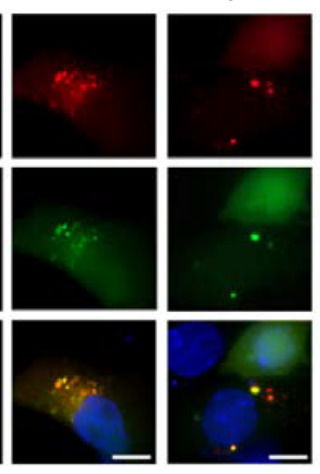

C
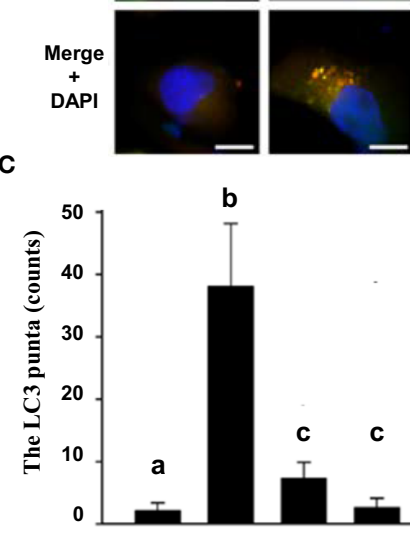

FIGURE 7 | Delayed autophagosome formation by BEFV is suppressed by 5 -aminoimidazole-4-carboxamide-1- $\beta$-riboside (AICAR) or aspirin. (A) MDBK cells were infected with BEFV at an $\mathrm{MOI}$ of 1 with or without pretreatment of AICAR $(1 \mathrm{mM})$ and aspirin $(5 \mathrm{mM})$, respectively. Cell lysates were collected at the indicated time points and subjected to immunoblotting with the respective antibodies. The levels of indicated proteins in the mock group were considered onefold. The activation and inactivation folds indicated below each lane were normalized against values for the mock control group. $\beta$-actin was used for the internal control for normalization. All experiments were conducted in three independent experiments. Signals in all Western blots were quantified with ImageJ software. The predicted size of each protein was labeled at the right-hand side in $\mathrm{kDa}$. (B) Induction of autophagy in MDBK cells expressing the mCherry-GFP-LC3 protein was monitored after pretreatment with AICAR or aspirin, respectively, for $30 \mathrm{~min}$ and then infected with BEFV at an MOI of 1 for $18 \mathrm{~h}$. LC3 fluorescent puncta were observed using fluorescence microscopy. Cell nuclei were stained with DAPI. Scale bars, $25 \mathrm{~mm}$. (C) The numbers of LC3 punta were calculated from the results from panel (B). Significance between the treatments was determined by Duncan's Multiple Range Test (MDRT) using SPSS software (Version 20.0). Means with common alphabets $(a, b, c)$ denotes no significance at $p<0.05$. Each value represents mean $\pm S E$ of three independent experiments.

phospholipid to arachidonic acid by phospholipase A2. Arachidonic acid is converted to $\mathrm{PGH} 2$ via cyclooxygenase (Cox-1/Cox-2). Prostaglandin E2 is isomerized from PGH2 by tissue specific prostaglandin E synthases $(66,67)$. PGE2 binds to its corresponding receptors (EP1-4) to act on cells with a wide variety of effects. By modulating inflammation and the immune system through regulating cytokines, the influence on viral infection is virus-family-dependent (68). Our previous studies suggested that BEFV stimulates the Cox-2-mediated PGE2/EP receptor signalling pathways to amplify the Src/JNK pathway for cell entry and autophagy induction $(7,12)$. In the present study, we further found that AICAR reversed BEFV-mediated increased Cox-2 expression and PGE2 production, thereby inhibiting autophagy and virus yield. Suppression of Cox-2 expression by AICAR has been reported $(63,69,70)$. Our findings are consistent with these studies. Aspirin blocks the function of Cox-2 to decrease PEG2 production. Reduction of BEFV-triggered PGE2 production by both AICAR and aspirin is through different mechanisms.
At the early stage of infection, both Src/JNK/AP-1 and PI3K/ Akt/NF- $\kappa B$ pathways are up-regulated to induce autophagy. As illustrated in Figure 8, AICAR reverses the BEFV-activated signaling pathways at the early and late stages of infection in a AMPK-independent manner. Furthermore, the ATG-related proteins including ULK1, Beclin 1, ATG7, and LC3 were all suppressed in AICAR-treated but not in aspirin-treated cells. At the late stage of infection, AICAR reversed the BEFV-activated Src/JNK/AP-1 and BEFV-suppressed PI3K/Akt/mTORC1 pathways, but aspirin did not regulate the Src/JNK/AP-1 pathway. Although the BEFV-activated PI3K/Akt pathway at the early stage of infection was not suppressed by aspirin, there was still moderate suppression of NF- $\kappa \mathrm{B}$ by aspirin. The inhibition is granted by the innate ability of aspirin, since salicylate inhibition of the NF- $\mathrm{BB}$ pathway has been well recognized for a decade $(71,72)$.

Aspirin is a widely and historically used medication. It is utilized for analgesic, anti-inflammation and anti-thrombosis properties due to inhibition of Cox-1 and Cox-2 activity. Recent studies suggested 
The early stage of BEFV infection

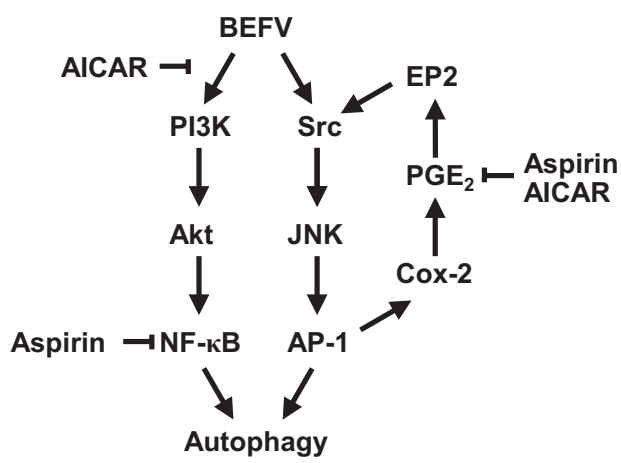

The late stage of BEFV infection

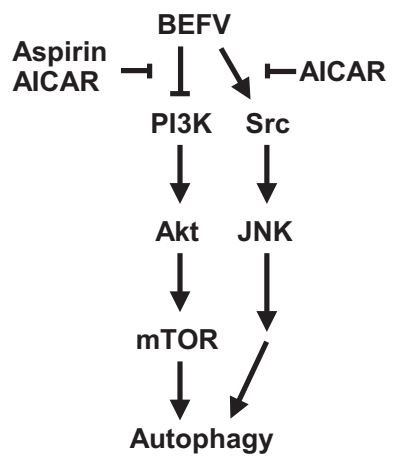

FIGURE 8 | Models illustrating the mechanisms of AICAR and aspirin-mediated inhibition of BEFV-induced autophagy. At the early stage of BEFV infection, AICAR suppresses the BEFV-activated PI3K/Akt/NF-KB and Src/JNK/AP-1/Cox-2/PGE2/EP2 pathways, and aspirin suppresses NF-KB and the BEFV-activated Src/JNK/ AP-1/Cox-2/PGE2/EP2 pathway. At the late stage of BEFV infection, AICAR reverses the BEFV-inactivated PI3K/Akt/mTOR pathway and the BEFV-activated Src/ JNK/Bcl-2 pathway while aspirin reverses the BEFV-inactivated PI3K/Akt/mTOR pathway.

that aspirin serves as a chemopreventive agent according to the Cox-independent mechanisms including inhibition of $\mathrm{NF}-\kappa \mathrm{B}$, interruption of extracellular signal-regulated kinases (ERK), induction of apoptosis by caspase activation and inhibition of the Wnt/b-catenin pathway (73). Thus, the possible applications of aspirin are more than just as a Cox inhibitor. Several studies revealed that aspirin induces autophagy in murine hepatocarcinoma, sarcoma (74), and colorectal cancer cells (75), and inhibits histone acetyltransferase (EP300) to induce autophagy (76). Conversely, aspirin may inhibit autophagy in epithelial cells of the gastrointestinal tract (77) and alleviates cardiac fibrosis in mice by inhibiting autophagy (78). The antiviral ability of aspirin has been previously reported, including influenza $(79,80)$, cytomegalovirus (81), RNA viruses of the respiratory tract (82), feline foamy virus (83), and Zika Virus (84); however, the underlying mechanisms remain largely unknown. Our study demonstrats that aspirin inhibits BEFV replication by inhibiting BEFV-induced autophagy via suppression of the BEFV-activated Src/JNK/AP-1 pathway and its NF- $\mathrm{KB}$-inhibiting activity and revision of the BEFV-suppressed PI3K/Akt/ mTORC1 pathway.

The current study provides novel insights into aspirin- and AICAR-impeded virus replication by inhibiting BEFV-induced autophagy via suppression of the PI3K/Akt/NF- $\mathrm{KB}$ and Src/JNK pathways as well as reversion of the BEFV-inactivated PI3K/Akt/ mTORC1 pathway. Hypothesized models for suppression of BEFV-induced autophagy by aspirin and AICAR are shown in Figure 8. The present study provides an option for treatment of BEF by aspirin and AICAR.

\section{REFERENCES}

1. Nandi S, Negi BS. Bovine ephemeral fever: a review. Comp Immunol Microbiol Infect Dis (1999) 22:81-91. doi: 10.1016/S0147-9571(98)00027-7

2. Walker PJ, Klement E. Epidemiology and control of bovine ephemeral fever. Vet Res (2015) 46:124. doi: 10.1186/s13567-015-0262-4

\section{DATA AVAILABILITY STATEMENT}

The original contributions presented in the study are included in the article. Further inquiries can be directed to the corresponding authors.

\section{AUTHOR CONTRIBUTIONS}

H-HT, W-RH, C-YC, and H-CC performed most of the experiments. H-HT, W-RH, B-LN, T-LL and H-JL analyzed the data. H-JL conceived and designed the experiments, wrote the paper, and supervised the project. $\mathrm{H}-\mathrm{JL}$ and B-LN revised and edited the manuscript. All authors contributed to the article and approved the submitted version.

\section{FUNDING}

This work was financially supported by the Ministry of Science and Technology of Taiwan (MOST 109-2313-B-005-006-MY3), the iEGG and Animal Biotechnology Center from The Feature Areas Research Center Program within the framework of the Higher Education Sprout Project by the Ministry of Education (MOE) in Taiwan (109S0023A), the Taichung Veterans General Hospital (TCVGH-NCHU1097602), and the National Chung Hsing University (TCVGH-NCHU1097602).

3. Murphy FA, Taylor WP, Mims CA, Whitfield SG. Bovine ephemeral fever virus in cell culture and mice. Arch Gesamte Virusforsch (1972) 38:234-49. doi: 10.1007/BF01249675

4. Walker PJ, Byrne KA, Cybinski DH, Doolan DL, Wang YH. Proteins of bovine ephemeral fever virus. J Gen Virol (1991) 72:67-74. doi: 10.1099/0022$1317-72-1-67$ 
5. Chiu HC, Huang WR, Wang YY, Li JY, Liao TL, Nielsen B, et al. Heterogeneous nuclear ribonucleoprotein $\mathrm{Al}$ and lamin $\mathrm{A} / \mathrm{C}$ modulate nucleocytoplasmic shuttling of avian reovirus p17. J Virol (2019) 93(20): e00851-19. doi: 10.1128/JVI.00851-19

6. Graham SC, Assenberg R, Delmas O, Verma A, Gholami A, Talbi C, et al. Rhabdovirus matrix protein structures reveal a novel mode of self-association. PloS Pathog (2008) 4(12):e1000251. doi: 10.1371/journal.ppat.1000251

7. Cheng CY, Tseng HH, Chiu HC, Chang CD, Nielsen BL, Liu HJ. Bovine ephemeral fever virus triggers autophagy enhancing virus replication via upregulation of the Src/JNK/AP1 and PI3K/Akt/NF- $\mathrm{KB}$ pathways and suppression of the PI3K/Akt/mTOR pathway. Vet Res (2019) 50(1):79. doi: 10.1186/s13567-019-0697-0

8. Diehl N, Schaal H. Make yourself at home: Viral hijacking of the PI3K/Akt signaling pathway. Viruses (2013) 5(12):3192-12. doi: 10.3390/v5123192

9. Ji WT, Liu H. PI3K-Akt signaling and viral infection. Recent Pat Biotechnol (2008) 2(3):218-26. doi: 10.2174/187220808786241042

10. Ji WT, Wang YC, Lin FL, Liao MH, Shih WL, Liu HJ. Inhibitors of phosphatidylinositol 3-kinase and mTOR but not Akt enhance replication of bovine ephemeral fever virus. Vet $J$ (2011) 187(1):119-23. doi: 10.1016/ j.tvjl.2009.11.003

11. Cheng CY, Shih WL, Huang WR, Chi PI, Wu MH, Liu HJ. Bovine ephemeral fever virus uses a clathrin-mediated and dynamin 2-dependent endocytic pathway that requires Rab5 and Rab7 as well as microtubules for endocytosis. J Virol (2012) 86(24):13653-61. doi: 10.1128/JVI.01073-12

12. Cheng CY, Huang WR, Chi PI, Chiu HC, Liu HJ. Cell entry of bovine ephemeral fever virus requires activation of Src-JNK-AP1 and PI3K-Akt-NF$\mathrm{\kappa B}$ pathways as well as Cox-2-mediated PGE2/EP receptor signalling to enhance clathrin-mediated virus endocytosis. Cell Microbiol (2015) 17 (7):967-87. doi: $10.1111 / \mathrm{cmi} .12414$

13. Baigent C, Patrono C. Selective cyclooxygenase 2 inhibitors, aspirin, and cardiovascular disease: a reappraisal. Arthritis Rheumatol (2003) 48(1):12-20. doi: 10.1002/art.10738

14. Alers S, Löffler AS, Wesselborg S, Stork B. Role of AMPK-mTOR-Ulk1/2 in the regulation of autophagy: cross talk, shortcuts, and feedbacks. Mol Cell Biol (2012) 32(1):2-11. doi: 10.1128/MCB.06159-11

15. Rabanal-Ruiz Y, Otten EG, Korolchuk VI. mTORC1 as the main gateway to autophagy. Essays Biochem (2017) 61(6):565-84. doi: 10.1042/EBC20170027

16. Russell RC, Yuan HX, Guan KL. Autophagy regulation by nutrient signaling. Cell Res (2014) 24(1):42-57. doi: 10.1038/cr.2013.166

17. Meijer AJ, Codogno P. Autophagy: regulation by energy sensing. Curr Biol (2011) 21(6):R227-9. doi: 10.1016/j.cub.2011.02.007

18. Roach PJ. AMPK $\rightarrow$ ULK1 $\rightarrow$ Autophagy. Mol Cell Biol (2011) 15):3082-84. doi: 10.1128/MCB.05565-11

19. Kim J, Yang G, Kim Y, Kim J, Ha J. AMPK activators: mechanisms of action and physiological activities. Exp Mol Med (2016) 48:e224. doi: 10.1038/emm.2016.16

20. Corton JM, Gillespie JG, Hawley SA, Hardie DG. 5-aminoimidazole-4carboxamide ribonucleoside. A specific method for activating AMP-activated protein kinase in intact cells. Eur J Biochem (1995) 229(2):558-65. doi: 10.1111/ j.1432-1033.1995.tb20498.x

21. Chi PI, Huang WR, Chiu HC, Li JY, Nielsen BL, Liu HJ. Avian reovirus sigmaA-modulated suppression of lactate dehydrogenase and upregulation of glutaminolysis and the mTOC1/eIF4E/HIF-1alpha pathway to enhance glycolysis and the TCA cycle for virus replication. Cell Microbiol (2018) 20: e12946. doi: $10.1111 / \mathrm{cmi} .12946$

22. Kim PB, Nelson JW, Breaker RR. An ancient riboswitch class in bacteria regulates purine biosynthesis and one-carbon metabolism. Mol Cell (2015) 57 (2):317-28. doi: 10.1016/j.molcel.2015.01.001

23. Łabuzek K, Liber S, Gabryel B, Okopień B. AICAR (5-aminoimidazole-4carboxamide-1-beta-4-ribofuranoside) increases the production of toxic molecules and affects the profile of cytokines release in LPS-stimulated rat primary microglial cultures. Neurotoxicology (2010) 31(1):134-46. doi: 10.1016/j.neuro.2009.10.006

24. Wang $\mathrm{K}$, Shindoh $\mathrm{H}$, Inoue $\mathrm{T}$, Horii I. Advantages of in vitro cytotoxicity testing by using primary rat hepatocytes in comparison with established cell lines. J Toxicol Sci (2002) 27(3):229-37. doi: 10.2131/jts.27.229

25. Rouzer CA, Marnett LJ. Non-redundant functions of cyclooxygenases: oxygenation of endocannabinoids. J Biol Chem (2008) 283(13):8065-69. doi: $10.1074 / j b c . R 800005200$

26. Futak N, Takahashi S, Yokoyama M, Arai I, Higuchi S, Otomo S. NS-398, a new anti-inflammatory agent, selectively inhibits prostaglandin $\mathrm{G} / \mathrm{H}$ synthase/ cyclooxygenase (COX-2) activity in vitro. Prostaglandins (1994) 47(1):55-9. doi: 10.1016/0090-6980(94)90074-4

27. Ferguson S, Hébert RL, Laneuville O. NS-398 upregulates constitutive cyclooxygenase- 2 expression in the M-1 cortical collecting duct cell line. J Am Soc Nephrol (1999) 10(11):2261-71.

28. Elder DJ, Halton DE, Crew TE, Paraskeva C. Apoptosis induction and cyclooxygenase-2 regulation in human colorectal adenoma and carcinoma cell lines by the cyclooxygenase-2-selective non-steroidal anti-inflammatory drug NS-398. Int J Cancer (2000) 86(4):553-60. doi: 10.1002/(SICI)1097-0215 (20000515)86:4<553::AID-IJC18>3.0.CO;2-9

29. Pang L, Nie M, Corbett L, Knox AJ. Cyclooxygenase-2 expression by nonsteroidal anti-inflammatory drugs in human airway smooth muscle cells: role of peroxisome proliferator-activated receptors. J Immunol (2003) 170(2):1043-51. doi: 10.4049/jimmunol.170.2.1043

30. Mitchell JA, Akarasereenont P, Thiemermann C, Flower RJ, Vane JR. Selectivity of nonsteroidal antiinflammatory drugs as inhibitors of constitutive and inducible cyclooxygenase. Proc Natl Acad Sci USA (1993) 90(24):11693-97. doi: 10.1073/pnas.90.24.11693

31. Kawashima M, Ogura N, Akutsu M, Ito K, Kondoh T. The anti-inflammatory effect of cyclooxygenase inhibitors in fibroblast-like synoviocytes from the human temporomandibular joint results from the suppression of PGE2 production. J Oral Pathol Med (2013) 42(6):499-06. doi: 10.1111/jop.12045

32. Moon CM, Kwon JH, Kim JS, Oh SH, Lee KJ, Park JJ, et al. Nonsteroidal antiinflammatory drugs suppress cancer stem cells via inhibiting PTGS2 (cyclooxygenase 2) and NOTCH/HES1 and activating PPARG in colorectal cancer. Int J Cancer (2014) 134(3):519-29. doi: 10.1002/ijc.28381

33. Sun $\mathrm{L}$, Chen $\mathrm{K}$, Jiang Z, Chen X, Ma J, Ma Q, et al. Indometacin inhibits the proliferation and activation of human pancreatic stellate cells through the downregulation of COX-2. Oncol Rep (2018) 39(5):2243-51. doi: 10.3892/ or.2018.6321

34. Mizushima N. Autophagy: process and function. Genes Dev (2007) 21 (22):2861-73. doi: 10.1101/gad.1599207

35. Pattingre S, Tassa A, Qu X, Garuti R, Liang XH, Mizushima N, et al. Bcl-2 antiapoptotic proteins inhibit Beclin 1-dependent autophagy. Cell (2005) 122 (6):927-39. doi: 10.1016/j.cell.2005.07.002

36. Wei Y, Pattingre S, Sinha S, Bassik M, Levine B. JNK1-mediated phosphorylation of Bcl-2 regulates starvation-induced autophagy. Mol Cell (2008) 30(6):678-88. doi: 10.1016/j.molcel.2008.06.001

37. Liu WJ, Ye L, Huang WF, Guo LJ, Xu ZG, Wu HL, et al. P62 links the autophagy pathway and the ubiqutin-proteasome system upon ubiquitinated protein degradation. Cell Mol Biol Lett (2016) 21:29. doi: 10.1186/s11658-016-0031-z

38. Eskelinen EL. Maturation of autophagic vacuoles in Mammalian cells. Autophagy (2005) 1(1):1-10. doi: 10.4161/auto.1.1.1270

39. Glick D, Barth S, Macleod KF. Autophagy: cellular and molecular mechanisms. J Pathol (2010) 221(1):3-12. doi: 10.1002/path.2697

40. Kudchodkar SB, Levine B. Viruses and autophagy. Rev Med Virol (2009) 19 (6):359-78. doi: 10.1002/rmv.630

41. Deretic V, Saitoh T, Akira S. Autophagy in infection, inflammation and immunity. Nat Rev Immunol (2013) 13(10):722-37. doi: 10.1038/nri3532

42. Chi PI, Huang WR, Lai IH, Cheng CY, Liu HJ. The p17 nonstructural protein of avian reovirus triggers autophagy enhancing virus replication via activation of phosphatase and tensin deleted on chromosome 10 (PTEN) and AMPactivated protein kinase (AMPK), as well as dsRNA-dependent protein kinase (PKR)/eIF2 $\alpha$ signaling pathways. J Biol Chem (2013) 288(5):3571-84. doi: 10.1074/jbc.M112.390245

43. Huang WR, Chi PI, Chiu HC, Hsu JL, Nielsen BL, Liao TL, et al. Avian reovirus p17 and sigma $\mathrm{A}$ act cooperatively to downregulate Akt by suppressing mTORC2 and $\mathrm{CDK} 2 /$ cyclin $\mathrm{A} 2$ and upregulating proteasome PSMB6. Sci Rep (2017) 7(1):5226. doi: 10.1038/s41598-017-05510-x

44. Wu Y, Cui L, Zhu E, Zhou W, Wang Q, Wu X, et al. Muscovy duck reovirus sigma NS protein triggers autophagy enhancing virus replication. Virol $J$ (2017) 14(1):53. doi: 10.1186/s12985-017-0722-8

45. Choi Y, Bowman JW, Jung JU. Autophagy during viral infection - a double-edged sword. Nat Rev Microbiol (2018) 16(6):341-54. doi: 10.1038/s41579-018-0003-6

46. Taisne C, Lussignol M, Hernandez E, Moris A, Mouna L, Esclatine A. Human cytomegalovirus hijacks the autophagic machinery and LC3 homologs in order to optimize cytoplasmic envelopment of mature infectious particles. $\mathrm{Sci}$ Rep (2019) 9:4560-72. doi: 10.1038/s41598-019-41029-Z 
47. Lv S, Xu QY, Sun EC, Zhang JK, Wu DL. Dissection and integration of the autophagy signaling network initiated by bluetongue virus infection: crucial candidates ERK1/2, Akt and AMPK. Sci Rep (2016) 6:23130. doi: 10.1038/ srep23130

48. Li M, Li J, Zeng R, Yang J, Liu J, Zhang Z, et al. Respiratory syncytial virus replication is promoted by autophagy-mediated inhibition of apoptosis. J Virol (2018) 92(8):e02193-17. doi: 10.1128/JVI.02193-17

49. Mankouri J, Tedbury PR, Gretton S, Hughes ME, Griffin SD, Dallas ML, et al. Enhanced hepatitis $\mathrm{C}$ virus genome replication and lipid accumulation mediated by inhibition of AMP-activated protein kinase. Proc Natl Acad Sci USA (2010) 107(25):11549-54. doi: 10.1073/pnas.0912426107

50. Lo AK, Lo KW, Ko CW, Young LS, Dawson CW. Inhibition of the LKB1AMPK pathway by the Epstein-Barr virus-encoded LMP1 promotes proliferation and transformation of human nasopharyngeal epithelial cells. J Pathol (2013) 230(3):336-46. doi: 10.1002/path.4201

51. Martin C, Leyton L, Arancibia Y, Cuevas A, Zambrano A, Concha MII, et al. Modulation of the AMPK/Sirt1 axis during neuronal infection by herpes simplex virus type 1. J Alzheimers Dis (2014) 42(1):301-12. doi: 10.3233/JAD-140237

52. Nakashima K, Takeuchi K, Chihara K, Hotta H, Sada K. Inhibition of hepatitis $\mathrm{C}$ virus replication through adenosine monophosphate-activated protein kinase-dependent and -independent pathways. Microbiol Immunol (2011) 55(11):774-82. doi: 10.1111/j.1348-0421.2011.00382.x

53. Leyton L, Hott M, Acuña F, Caroca J, Nuñez M, Martin C, et al. Nutraceutical activators of AMPK/Sirt1 axis inhibit viral production and protect neurons from neurodegenerative events triggered during HSV-1 infection. Virus Res (2015) 205:63-72. doi: 10.1016/j.virusres.2015.05.015

54. Xie W, Wang L, Dai Q, Yu H, He X, Xiong J, et al. Activation of AMPK restricts coxsackievirus B3 replication by inhibiting lipid accumulation. J Mol Cell Cardiol (2015) 85:155-67. doi: 10.1016/j.yjmcc.2015.05.021

55. Cheng F, He M, Jung JU, Lu C, Gao SJ. Suppression of Kaposi's sarcomaassociated herpesvirus infection and replication by 5 '-AMP-activated protein kinase. J Virol (2016) 90(14):6515-25. doi: 10.1128/JVI.00624-16

56. Xie N, Yuan K, Zhou L, Wang K, Chen HN, Lei Y, et al. PRKAA/AMPK restricts $\mathrm{HBV}$ replication through promotion of autophagic degradation. Autophagy (2016) 12(9):1507-20. doi: 10.1080/15548627.2016.1191857

57. Daignan-Fornier B, Pinson B. 5-aminoimidazole-4-carboxamide-1-beta-Dribofuranosyl 5'-monophosphate (AICAR), a highly conserved purine intermediate with multiple effects. Metabolites (2012) 2(2):292-02. doi: 10.3390/metabo2020292

58. Ducker GS, Rabinowitz JD. ZMP: a master regulator of one-carbon metabolism. Mol Cell (2015) 57(2):203-4. doi: 10.1016/j.molcel.2015.01.012

59. Vincent MF, Bontemps F, Van den Berghe G. Inhibition of glycolysis by 5amino-4-imidazolecarboxamide riboside in isolated rat hepatocytes. Biochem $J$ (1992) 281:267-72. doi: 10.1042/bj2810267

60. López JM, Santidrián AF, Campàs C, Gil J. 5-Aminoimidazole-4-carboxamide riboside induces apoptosis in Jurkat cells, but the AMP-activated protein kinase is not involved. Biochem J (2003) 370:1027-32. doi: 10.1042/bj20021053

61. Guigas B, Bertrand L, Taleux N, Foretz M, Wiernsperger N, Vertommen D, et al. 5-Aminoimidazole-4-carboxamide-1-beta-D-ribofuranoside and metformin inhibit hepatic glucose phosphorylation by an AMP-activated protein kinase-independent effect on glucokinase translocation. Diabetes (2006) 55(4):865-74. doi: 10.2337/diabetes.55.04.06.db05-1178

62. Sid B, Glorieux C, Valenzuela M, Rommelaere G, Najimi M, Dejeans N, et al. AICAR induces Nrf2 activation by an AMPK-independent mechanism in hepatocarcinoma cells. Biochem Pharmacol (2014) 91(2):168-80. doi: 10.1016/j.bcp.2014.07.010

63. Kuo CL, Ho FM, Chang MY, Prakash E, Lin WW. Inhibition of lipopolysaccharideinduced inducible nitric oxide synthase and cyclooxygenase- 2 gene expression by 5 aminoimidazole-4-carboxamide riboside is independent of AMP-activated protein kinase. J Cell Biochem (2008) 103(3):931-40. doi: 10.1002/jcb.21466

64. Kirchner J, Brüne B, Namgaladze D. AICAR inhibits NFאB DNA binding independently of AMPK to attenuate LPS-triggered inflammatory responses in human macrophages. Sci Rep (2018) 8(1):7801. doi: 10.1038/s41598-018-26102-3

65. Bergstroem S, Danielsson H, Samuelsson B. The enzymatic formation of prostaglandin E2 from arachidonic acid prostaglandins and related factors 32. Biochim Biophys Acta (1964) 90:207-10. doi: 10.1016/0304-4165(64)90145-X

66. Cha YI, Solnica-Krezel L, DuBois RN. Fishing for prostanoids: deciphering the developmental functions of cyclooxygenase-derived prostaglandins. Dev Biol (2006) 289(2):263-72. doi: 10.1016/j.ydbio.2005.10.013
67. Sato H, Taketomi Y, Murakami M. Metabolic regulation by secreted phospholipase A2. Inflammation Regen (2016) 36:7. doi: 10.1186/s41232-016-0012-7

68. Sander WJ, O'Neill HG, Pohl CH. Prostaglandin E2 as a modulator of viral infections. Front Physiol (2017) 8:89. doi: 10.3389/fphys.2017.00089

69. Ayasolla KR, Singh AK, Singh I. 5-aminoimidazole-4-carboxamide-1-beta-4ribofuranoside (AICAR) attenuates the expression of LPS- and Abeta peptideinduced inflammatory mediators in astroglia. J Neuroinflamm (2005) 2:21. doi: 10.1186/1742-2094-2-21

70. Park IJ, Lee YK, Hwang JT, Kwon DY, Ha J, Park OJ. Green tea catechin controls apoptosis in colon cancer cells by attenuation of $\mathrm{H}_{2} \mathrm{O}_{2}$-stimulated COX-2 expression via the AMPK signaling pathway at low-dose $\mathrm{H}_{2} \mathrm{O}_{2}$. Ann NY Acad Sci (2009) 1171:538-44. doi: 10.1111/j.1749-6632.2009.04698.x

71. Kopp E, Ghosh S. Inhibition of NF-kappa B by sodium salicylate and aspirin. Science (1994) 265(5174):956-9. doi: 10.1126/science.8052854

72. Frantz B, O'Neill EA. The effect of sodium salicylate and aspirin on NF-kappa B. Science (1995) 270(5244):2017-19. doi: 10.1126/science.270.5244.2017

73. Dovizio M, Bruno A, Tacconelli S, Patrignani P. Mode of action of aspirin as a Chemopreventive Agent. Recent Results Cancer Res (2013) 191:39-65. doi: 10.1007/978-3-642-30331-9_3

74. Zhao Q, Wang Z, Wang Z, Wu L, Zhang W. Aspirin may inhibit angiogenesis and induce autophagy by inhibiting mTOR signaling pathway in murine hepatocarcinoma and sarcoma models. Oncol Lett (2016) 12(4):2804-10. doi: 10.3892/ol.2016.5017

75. Din FV, Valanciute A, Houde VP, Zibrova D, Green KA, Sakamoto K, et al. Aspirin inhibits mTOR signaling, activates AMP-activated protein kinase, and induces autophagy in colorectal cancer cells. Gastroenterology (2012) 142 (7):1504-15. doi: 10.1053/j.gastro.2012.02.050

76. Pietrocola F, Castoldi F, Markaki M, Lachkar S, Chen G, Enot DP, et al. Aspirin recapitulates features of caloric restriction. Cell Rep (2018) 22 (9):2395-07. doi: 10.1016/j.celrep.2018.02.024

77. Hernández C, Barrachina MD, Vallecillo-Hernández J, Álvarez Á, OrtizMasiá D, Cosín-Roger J, et al. aspirin-induced gastrointestinal damage is associated with an inhibition of epithelial cell autophagy. J Gastroenterol (2016) 51(7):691-01. doi: 10.1007/s00535-015-1137-1

78. Liu PP, Liu HH, Sun SH, Shi XX, Yang WC, Su GH, et al. Aspirin alleviates cardiac fibrosis in mice by inhibiting autophagy. Acta Pharmacol Sin (2017) 38 (4):488-97. doi: 10.1038/aps.2016.143

79. Huang RT, Dietsch E. Anti-influenza viral activity of aspirin in cell culture. N Engl J Med (1988) 319(12):797. doi: 10.1056/NEJM198809223191218

80. Mazur I, Wurzer WJ, Ehrhardt C, Pleschka S, Puthavathana P, Silberzahn T, et al. Acetylsalicylic acid (ASA) blocks influenza virus propagation via its NFkappaB-inhibiting activity. Cell Microbiol (2007) 9(7):1683-94. doi: 10.1111/ j.1462-5822.2007.00902.x

81. Speir E, Yu ZX, Ferrans VJ, Huang ES, Epstein SE. Aspirin attenuates cytomegalovirus infectivity and gene expression mediated by cyclooxygenase-2 in coronary artery smooth muscle cells. Circ Res (1998) 83(2):210-16. doi: 10.1161/01.RES.83.2.210

82. Glatthaar-Saalmüller B, Mair KH, Saalmüller A. Antiviral activity of aspirin against RNA viruses of the respiratory tract-an in vitro study. Influenza Other Respir Viruses (2017) 11(1):85-92. doi: 10.1111/irv.12421

83. Lee GE, Shin CG. Influence of pretreatment with immunosuppressive drugs on viral proliferation. J Microbiol Biotechnol (2018) 28(10):1716-22. doi: 10.4014/jmb.1807.06054

84. Pan T, Peng Z, Tan L, Zou F, Zhou N, Liu B, et al. Nonsteroidal antiinflammatory drugs potently inhibit the replication of Zika viruses by inducing the degradation of axl. J Virol (2018) 92(20):e01018-18. doi: 10.1128/JVI.01018-18

Conflict of Interest: The authors declare that the research was conducted in the absence of any commercial or financial relationships that could be construed as a potential conflict of interest.

Copyright $\odot 2020$ Tseng, Huang, Cheng, Chiu, Liao, Nielsen and Liu. This is an openaccess article distributed under the terms of the Creative Commons Attribution License (CC BY). The use, distribution or reproduction in other forums is permitted, provided the original author(s) and the copyright owner(s) are credited and that the original publication in this journal is cited, in accordance with accepted academic practice. No use, distribution or reproduction is permitted which does not comply with these terms. 